\title{
Considerations for Corridor and Community DC Fast Charging Complex System Design
}

\author{
Jim Francfort ${ }^{1}$ \\ Shawn Salisbury ${ }^{1}$ \\ John Smart ${ }^{1}$ \\ Thomas Garetson ${ }^{2}$ \\ Donald Karner ${ }^{2}$ \\ ${ }^{1}$ Idaho National Laboratory \\ ${ }^{2}$ Electric Applications Incorporated
}

May 2017

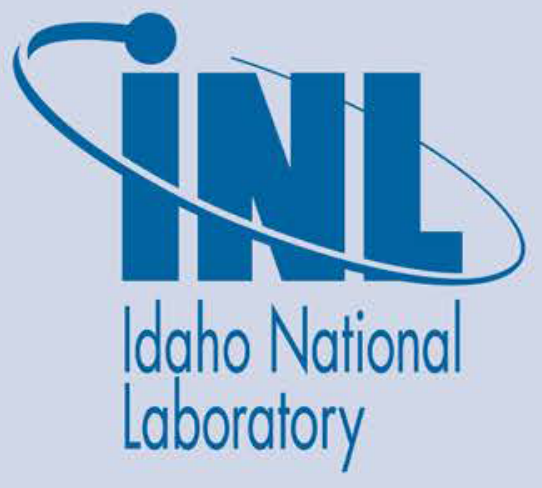

The INL is a U.S. Department of Energy National Laboratory operated by Battelle Energy Alliance 


\section{DISCLAIMER}

This information was prepared as an account of work sponsored by an agency of the U.S. Government. Neither the U.S. Government nor any agency thereof, nor any of their employees, makes any warranty, expressed or implied, or assumes any legal liability or responsibility for the accuracy, completeness, or usefulness, of any information, apparatus, product, or process disclosed, or represents that its use would not infringe privately owned rights. References herein to any specific commercial product, process, or service by trade name, trade mark, manufacturer, or otherwise, does not necessarily constitute or imply its endorsement, recommendation, or favoring by the U.S. Government or any agency thereof. The views and opinions of authors expressed herein do not necessarily state or reflect those of the U.S. Government or any agency thereof. 


\title{
Considerations for Corridor and Community DC Fast Charging Complex System Design
}

\author{
Jim Francfort ${ }^{1}$ \\ Shawn Salisbury ${ }^{1}$ \\ John Smart ${ }^{1}$ \\ Thomas Garetson ${ }^{2}$ \\ Donald Karner ${ }^{2}$
}

March 2017

\begin{abstract}
Idaho National Laboratory
Idaho Falls, Idaho 83415
\end{abstract}

https://avt.inl.gov

Prepared for the

U.S. Department of Energy

Under DOE Idaho Operations Office

Contract DE-AC07-05ID14517

${ }^{1}$ Idaho National Laboratory

${ }^{2}$ Electric Applications Incorporated 


\section{EXECUTIVE SUMMARY}

As auto manufacturers bring vehicles to market with large batteries that provide over 200 miles of driving range, interest in faster charging options for plug-in electric vehicles (PEVs) is intensifying. This report focuses on direct current fast charger (DCFC) systems and how they can be deployed to provide convenient charging for PEV drivers. First, lessons learned from previous DCFC deployment and data collection activities are shared to describe consumer experience with DCFC systems to date. Second, considerations and criteria are established for designing and upgrading DCFC complexes that provide fast-charging opportunities for PEV drivers in urban communities and on rural corridors. Third, cost estimates are shared for hypothetical high-power DCFC complexes that meet simplified design requirements. Finally, results for a business case analysis are presented that shed light on the financial challenges associated with DCFCs.

\section{Lessons Learned}

Fast-charging modern PEVs coincided with the beginning of The EV Project in 2011. Frequent use of DCFCs installed during this project by PEV owners illustrated how important DCFC availability is to the mass market. Because of this, the U.S. Department of Energy and others have conducted studies and surveys on deployment and use of DCFC equipment. Findings and lessons learned from these studies and surveys may be used to inform the design of DCFC equipment and networks to support faster charging of the longer-range vehicles of the future. The following list includes some of those lessons learned:

- DCFCs are most useful when they are sited within a half mile of major transportation corridors where they can support both intra and inter-urban travel. Most PEV drivers in The EV Project used DCFCs within cities during short-distance outings; however, they also demonstrated use of DCFCs located on corridors to extend their driving well beyond the single-charge range of their vehicles.

- During The EV Project, most fast charging occurred after typical work hours from 4 to 7 p.m. The vast majority of charge sessions lasted between 5 and 25 minutes, with half of all DCFC charge sessions lasting 20 minutes or less. Therefore, DCFCs will be more attractive when co-located with a host site that accommodates short-term visits (e.g., a coffee shop or convenience store).

- There is a greater likelihood that a DCFC will be highly utilized if it is located at or near a workplace where employees are likely to own PEVs, such that it can serve as a workplace charger in addition to providing access to the general public.

- Numerous installation challenges have become apparent during past deployment activities, including the following:

- Private investment in public charging stations is often not profitable under current market conditions because the revenues earned from offering public charging services have not offset the costs of purchasing, installing, and operating the stations within a typically attractive payback period of 5 years.

- Many DCFC installations required new electrical service to be added to the host's site. The cost of these installations was significantly higher than those that did not require new service. The total cost increased due to fees charged by the local electric utility to extend the service from the grid to the host site and/or install new service equipment. For transportation corridors, charging sites sometimes need to be located in sparsely populated areas where existing electrical service is minimal. The cost to establish new electrical service may become a significant barrier for these types of installations.

- It is generally thought that the availability of public infrastructure provides consumer confidence against "range anxiety," or the perceived fear by battery electric vehicle drivers of becoming stranded once the battery is depleted; however, this availability means that infrastructure must naturally precede the adoption of PEVs. Proliferation of charging infrastructure appears to be happening in 
areas that have the highest electric vehicle uptake, greater PEV model availability, and more state and local policy actions to support the market.

\section{Design Criteria for Community and Corridor Direct Current Fast Charger Complexes}

Criteria for design of DCFC complexes with multiple ports were developed to meet the needs of PEV drivers seeking convenient fast charging. Corridor DCFC complexes intended to support inter-urban travel may be located between urban centers and may be typically associated with other travel corridor facilities (e.g., truck stops, fast food restaurants, convenience stores, and tourist information centers). Complexes in urban communities are also important and are expected to serve three types of customers: (1) intra-urban travelers seeking a "top off" charge to continue their day's activities, (2) PEV owners who do not have regular overnight charging opportunities (e.g., residents of multi-unit dwellings), and (3) inter-urban travelers needing a charge upon reaching their destination or passing through an urban area on the way to a final destination.

Urban and rural sites can be similarly designed, albeit with components sized differently according to differences in expected customer demand for charging. A DCFC complex representing current technology and without onsite energy storage or generation would typically include the components shown in Figure ES-1. The alternating current (AC)/DC conversion, charger-to-vehicle communication, and power delivery are all performed within each fast charging unit.

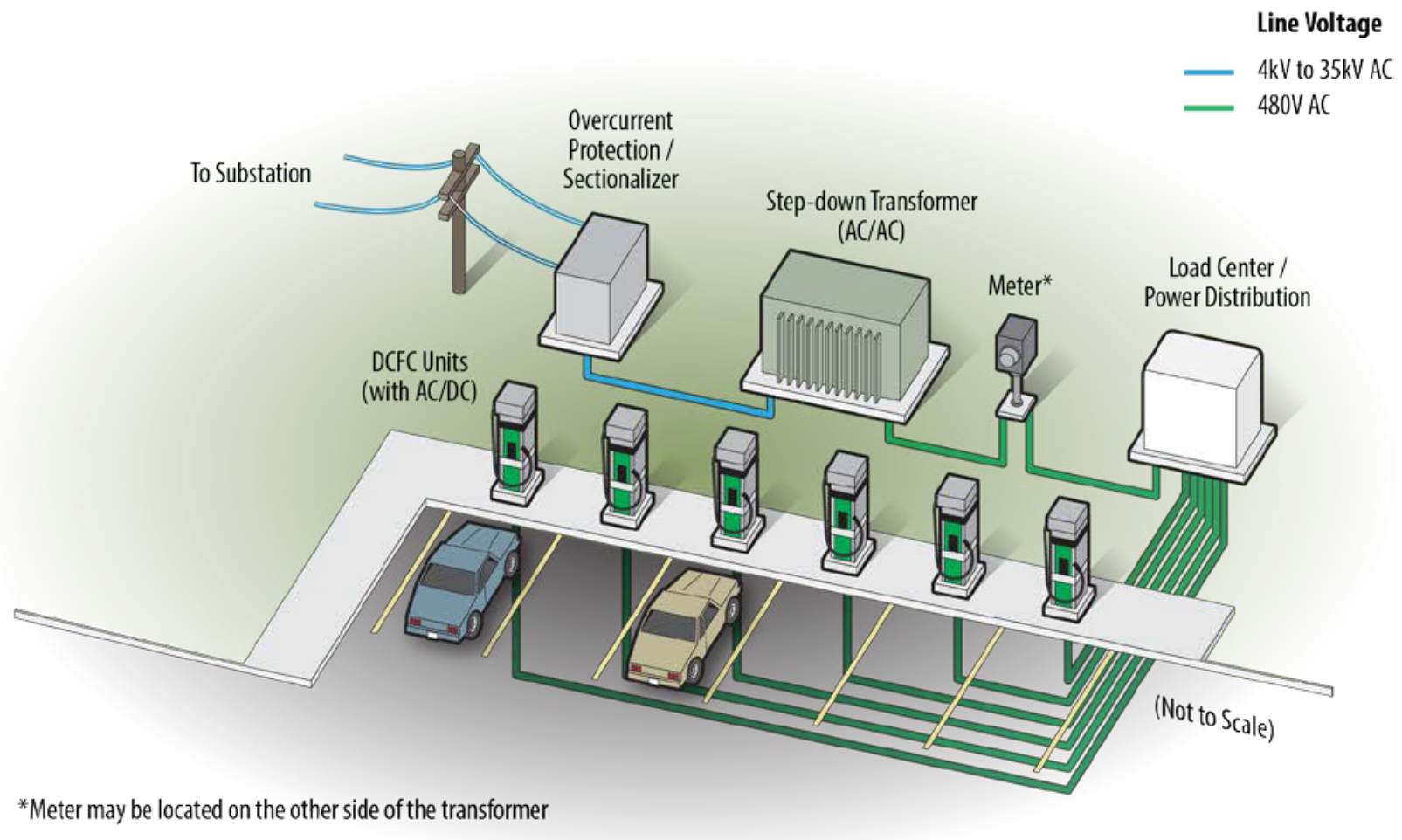

Figure ES-1. Diagram of a hypothetical multi-port DCFC complex.

In this design, each DCFC unit is supplied with 480 volts of alternating current (VAC) and the transformer, conduit, and conductors are sized based on the power capability of each charger and the number of chargers at the complex. A step-down transformer, which decreases voltage from the distribution voltage to the $480 \mathrm{VAC}$ required by the chargers, is typically located onsite. 
Adding onsite generation and energy storage (ES) to a DCFC site decouples the power provided to vehicles from power drawn from the grid. Generation and storage systems can be sized to allow vehicles to draw high power, while limiting the power drawn from the grid to limit electricity costs and minimize negative impacts on the grid. A schematic for a site with this capability is shown in Figure ES-2. In this system, the DCFC units, the ES system, and a photovoltaic (PV) solar array are all connected to a common high-voltage DC bus.

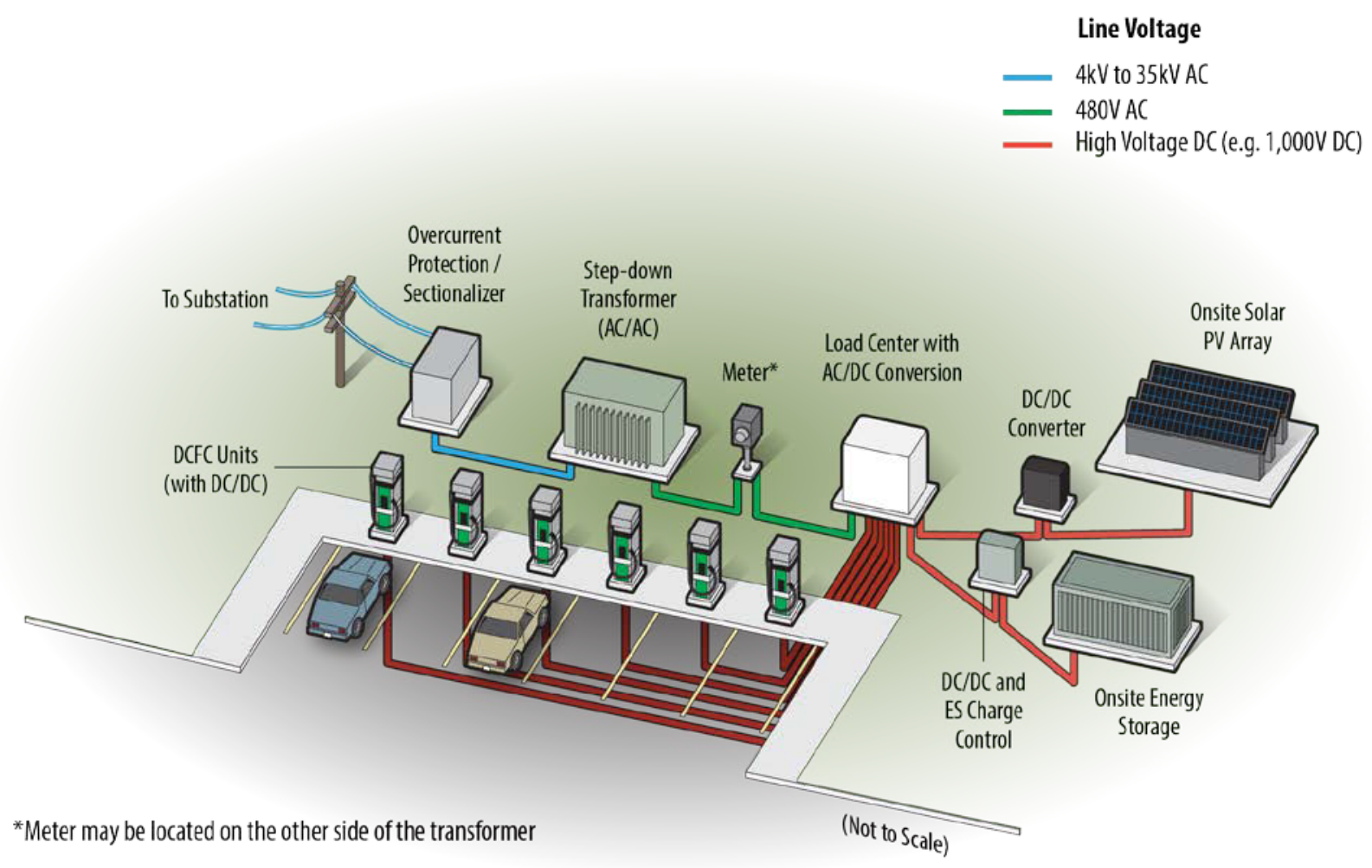

Figure ES-2. Diagram of a multi-port DCFC complex with onsite ES and solar PV systems.

\section{Upgradability}

In the near term, DCFC complexes should be designed to serve the hundreds of thousands of fastcharge-capable PEVs already on the road. Most of these vehicles can charge at $50 \mathrm{~kW}$ or less. Therefore, it may be tempting for designers to define equipment power requirements to support only $50-\mathrm{kW}$ charging to limit capital costs. However, designing for flexing and upgradability from the beginning may be a more prudent approach. To this end, the DCFC complex should be designed upfront to accommodate increased charge power, which is determined by the site's power supply, DCFC equipment power capability, and numerous other design factors. Because the future market for vehicles capable of high-power charging is uncertain, and because of the high capital cost of DCFC complexes, an upgrade strategy is not without risk. One of the purposes of this report is to elucidate the cost trade-offs of different DCFC complex upgrade strategies.

The first step toward understanding these trade-offs is to determine how the DCFC complex design may change with increasing charge power requirements. When increasing the power capability of the charging complex, several upgrades will be needed, including the following:

- Higher-capacity electrical equipment, such as the step-down transformer, load center, and AC/DC converter

- Larger or additional concrete pads to accommodate larger or new equipment 
- Upgraded or new DCFC units

- Conductors with higher current rating

- Larger diameter conduit.

Because of uncertainties in technology development timing and market demand, it may not be cost effective to initially size all DCFC complex components to meet expected future power demands. However, it may make sense for certain portions of the site to be constructed to accommodate future power expansion. Surface and underground work required to construct a DCFC complex (e.g., trenching for conduit, laying concrete pads, and construction of the transformer vault, if applicable) can incur significant cost because it is labor-intensive. During initial installation, conduit that can accommodate future power requirements should be laid to eliminate the need for re-trenching. Also, sizing concrete pads for higher power levels would reduce the cost of the upgrade process and ensure adequate space is reserved for future expansion. Figure ES-3 illustrates this strategy. Figure ES-3a depicts a DCFC complex with six DCFC units capable of 50-kW charging, without ES and PV systems. Conduit and concrete pads (highlighted in magenta) are sized during initial complex construction to prepare for a future upgrade to six $350-\mathrm{kW}$ chargers. In this example, all above-ground equipment would be upgraded in the future to support 350-kW charging, as shown in Figure ES-3b.

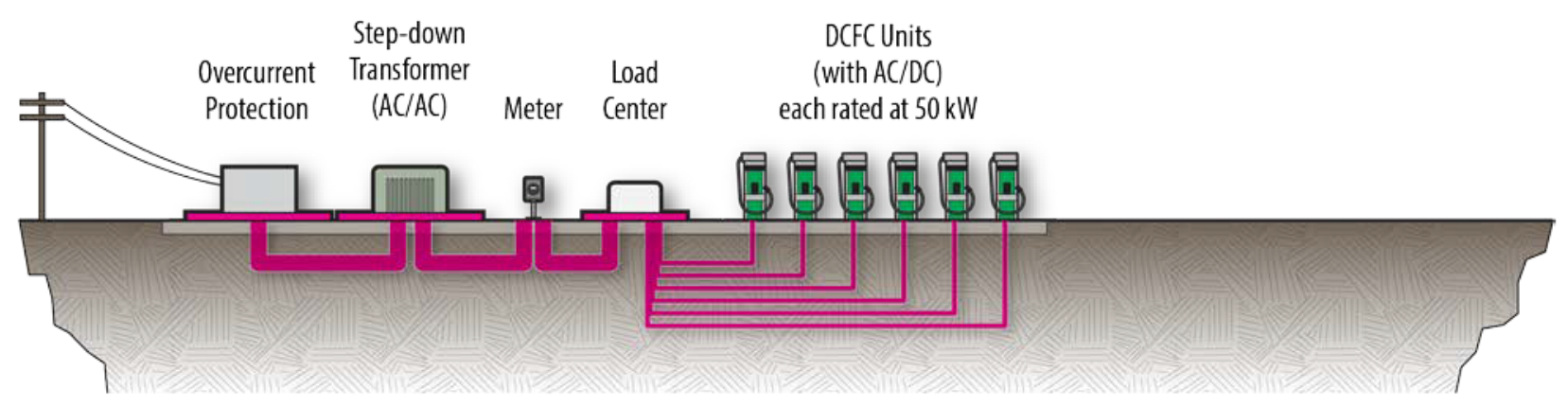

A) DCFC complex with 50-kW chargers and no ES and PV systems

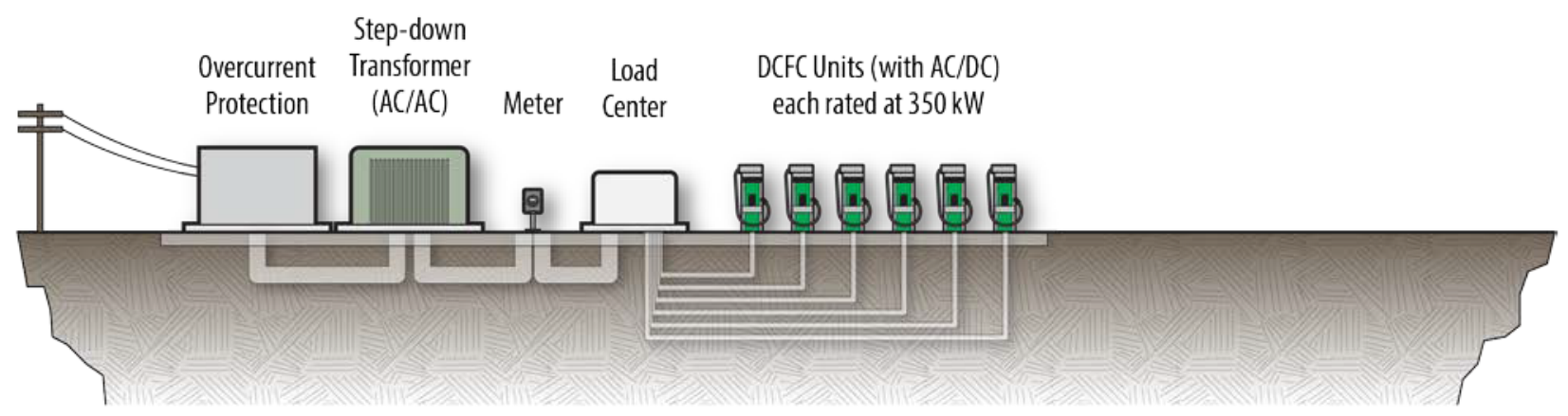

\section{B) DCFC complex with 350-kW chargers and no ES and PV systems}

Figure ES-3. Potential strategy for upgrade from 50-kW complex without ES and PV to 350-kW complex without ES and PV. Magenta highlights in Figure ES-3a show how surface and underground work should be over-built initially to preclude the need for rework upon future upgrade. Figure ES-3b shows the complex upgraded to the future design. 
If the end goal is to construct a DCFC complex that employs ES and PV systems to minimize the operational cost and grid impact of 350-kW charging, then the complex upgrade strategy should be different. Figure ES-4 illustrates an upgrade strategy for this case. Again, conduit and concrete pads are over-sized initially to avoid rework upon future upgrade, as indicated by magenta highlights in Figure ES4a, but sizes vary according to the different current/power ratings necessary for the future design. Also, additional conduit and cable are laid for future installation of ES and PV systems, shown in Figure ES-4b.

In addition to surface and underground work, above-ground electrical equipment could also be upgraded at the time of initial installation to avoid the need to replace the equipment later. However, note in Figure ES-3 how the size of the grid-side overcurrent protection device and step-down transformer change dramatically when the complex is upgraded to support $350-\mathrm{kW}$ charging, but they do not change in Figure ES-4. Appropriate upgrade strategies will vary based on future DCFC complex design requirements; therefore, it is vital to determine the future design of the complex, prior to initial complex construction. Otherwise, investment may be wasted by over-building the complex initially with more expensive, higher-capacity components that may never be needed.

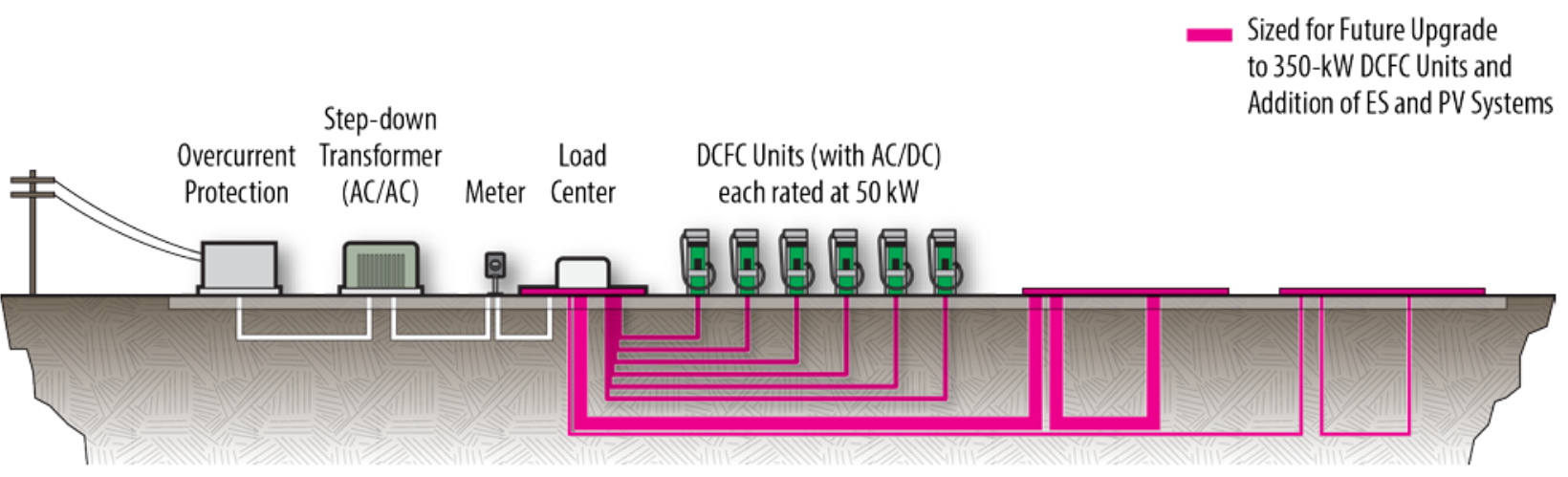

A) DCFC complex with 50-kW chargers and no ES and PV systems at initial installation

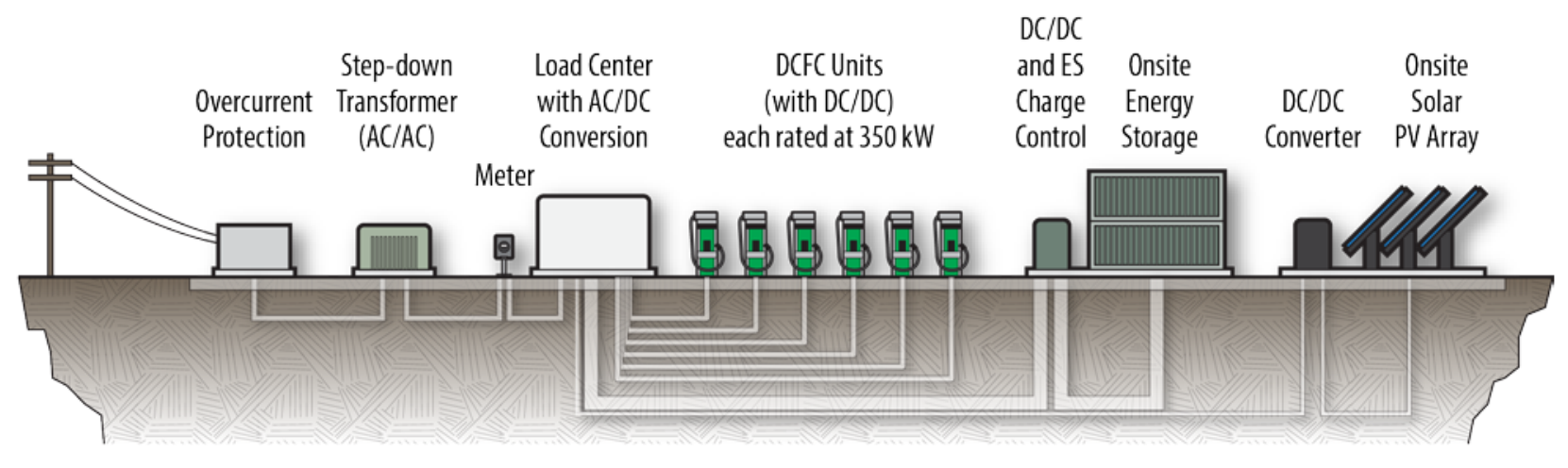

B) DCFC complex with 350-kW chargers and ES and PV systems

Figure ES-4. Potential strategy for upgrade from 50-kW complex without ES and PV to 350-kW complex with ES and PV. Magenta highlights in Figure ES-4a show how surface and underground work should be over-built initially to preclude the need for rework upon future upgrade. Figure ES-4b shows the complex upgraded to the future design. 


\section{Cost Estimation Case Study}

Hypothetical designs were developed for community and corridor complexes with and without ES and PV systems. Two cases were studied: "minimum capability" and "ultimate capability." For the minimum capability configuration, both the corridor and community charging complexes are equipped with six 50-kW DCFC units, allowing six vehicles to be connected to DCFC units simultaneously. ${ }^{1}$ Grid power is limited to $160 \mathrm{~kW}$ for the complex without ES and PV systems and to $110 \mathrm{~kW}$ for the complex with ES and PV systems. In the ultimate capability configuration, both the corridor and community charging stations are equipped with six $350-\mathrm{kW}$ charge units. Grid power is limited to $1,060 \mathrm{~kW}$ for the complex without ES and PV systems and to $210 \mathrm{~kW}$ for the complex with ES and PV systems. Capital and operating expenses for these complexes were calculated based on a multitude of factors and considerations, including equipment and installation costs, permitting and utility interconnection costs, monthly electricity cost, site lease cost, and equipment warranty cost. Tables ES-1 and ES-2 summarize the overall cost estimates.

Table ES-1. Summary of approximate costs for DCFC complexes meeting minimum capability requirements.

\begin{tabular}{|l|c|c|c|c|c|}
\hline & \multicolumn{4}{c|}{ Minimum Capability } \\
\hline Design Configuration & $\begin{array}{c}\text { Maximum } \\
\text { Grid Power } \\
(\mathbf{k W})\end{array}$ & $\begin{array}{c}\text { Capital } \\
\text { Cost }\end{array}$ & $\begin{array}{c}\text { Yearly } \\
\text { Operating } \\
\text { Cost }\end{array}$ & $\begin{array}{c}\text { Copital } \\
\text { Cost }\end{array}$ & $\begin{array}{c}\text { Yearly } \\
\text { Operating } \\
\text { Cost }\end{array}$ \\
\hline With ES and PV & 110 & $\$ 574,500$ & $\$ 170,600$ & $\$ 502,000$ & $\$ 163,000$ \\
\hline Without ES and PV & 160 & $\$ 392,000$ & $\$ 170,700$ & $\$ 385,500$ & $\$ 165,500$ \\
\hline
\end{tabular}

Table ES-2. Summary of approximate costs for DCFC complexes meeting ultimate capability requirements.

\begin{tabular}{|l|c|c|c|c|c|}
\hline \multicolumn{7}{|c|}{ Ultimate Capability } \\
\hline Design Configuration & $\begin{array}{c}\text { Maximum } \\
\text { Grid Power } \\
\text { (kW) }\end{array}$ & $\begin{array}{c}\text { Capital } \\
\text { Cost }\end{array}$ & $\begin{array}{c}\text { Yearly } \\
\text { Operating } \\
\text { Cost }\end{array}$ & $\begin{array}{c}\text { Capital } \\
\text { Cost }\end{array}$ & $\begin{array}{c}\text { Yearly } \\
\text { Operating } \\
\text { Cost }\end{array}$ \\
\hline With ES and PV & 210 & $\$ 2,030,500$ & $\$ 389,000$ & $\$ 1,636,500$ & $\$ 343,000$ \\
\hline Without ES and PV & 1,060 & $\$ 1,728,000$ & $\$ 514,500$ & $\$ 1,721,500$ & $\$ 500,500$ \\
\hline
\end{tabular}

For complexes meeting the minimum capability requirements, ES and PV systems add $\$ 99,500$ to $\$ 165,000$ in capital cost, but have little effect on operating costs. With ES and PV, a complex will pay less for electrical energy and demand, but these savings are offset due to increased maintenance and warranty costs from the added equipment. For this reason, it would be unlikely that a complex owner would benefit from installing ES and PV systems for a station meeting the minimum capability requirements. For corridor and community DCFC complexes meeting the ultimate requirements, Table ES-2 shows that operating costs are much lower for systems with ES and PV. With ES and PV systems, capital costs are higher for corridor complexes and lower for community complexes, when compared to their counterparts without ES and PV. The ES and PV systems add a large cost to the complex, especially

\footnotetext{
${ }^{1}$ For the purposes of this study, a single DCFC unit is capable of charging one vehicle at a time. Each unit may have multiple cord sets, each with a different style connector, but the DCFC units described in this report should be thought of as single-port units. Furthermore, a DCFC unit contains equipment necessary to supply rated power or reduced power to a single connected vehicle, based on power limits communicated to the charging unit by the vehicle and the complex.
} 
in the corridor case, but they also decrease DCFC unit hardware costs by allowing the removal of expensive power electronics. These results show that, given the assumptions used in this case study, it is more cost effective to employ the design with ES and PV systems for the ultimate capability scenarios.

The question about the most cost-effective way to upgrade from the minimum to the ultimate design remains. Examination of capital costs identified several items that could be pulled ahead to save money in the long run. Engineering, permitting, utility interconnection, site surface and underground work, and electrical equipment installation could be completed to meet the grid power requirement of the ultimate capability scenario when designing and building a DCFC complex to the minimum capability level. Later, upgrading only the DCFC units and adding ES and PV systems would be required to create a complex meeting the ultimate capability requirements. In this case study, this would add about $\$ 25,000$ to the upfront cost, but save $\$ 115,000$ to $\$ 120,000$ in total capital expenditure after upgrading the site to accommodate $350-\mathrm{kW}$ charging.

\section{Business Case Analysis}

In addition to understanding the relative costs of different DCFC complex designs, it is important to understand the business case for DCFC complexes. Business case analysis of fast charging complexes using ES and PV systems was completed as part of this case study using a tool developed by Atlas Public Policy. This included determining the cost that the owner-operator would need to charge customers for charging energy to financially break even. The results of the analysis are summarized in Table ES-3.

Table ES-3. End-user costs required for DCFC complex owner-operator to financially break even after 5 or 10 years, assuming revenue comes only from charging fees.

\begin{tabular}{|c|c|c|c|c|c|}
\hline \multirow[b]{2}{*}{$\begin{array}{l}\text { Payback } \\
\text { Period }\end{array}$} & \multirow[b]{2}{*}{ Customer Cost Metric } & \multicolumn{4}{|c|}{ Cost Required to Break Even After Payback Period } \\
\hline & & $\begin{array}{c}\text { Minimum } \\
\text { Corridor } \\
\text { Six 50-kW }\end{array}$ & $\begin{array}{l}\text { Minimum } \\
\text { Community } \\
\text { Six 50-kW }\end{array}$ & $\begin{array}{c}\text { Ultimate } \\
\text { Corridor } \\
\text { Six 350-kW }\end{array}$ & $\begin{array}{c}\text { Ultimate } \\
\text { Community } \\
\text { Six 350-kW }\end{array}$ \\
\hline \multirow{2}{*}{5 Years } & Electricity Cost $(\$ / \mathrm{kWh})$ & $\$ 0.88$ & $\$ 0.93$ & $\$ 1.04$ & $\$ 1.01$ \\
\hline & Equivalent Gasoline Cost (\$/gal) & $\$ 7.54$ & $\$ 7.91$ & $\$ 8.91$ & $\$ 8.65$ \\
\hline \multirow{2}{*}{10 Years } & Electricity Cost $(\$ / \mathrm{kWh})$ & $\$ 0.69$ & $\$ 0.73$ & $\$ 0.77$ & $\$ 0.76$ \\
\hline & Equivalent Gasoline Cost (\$/gal) & $\$ 5.91$ & $\$ 6.25$ & $\$ 6.60$ & $\$ 6.51$ \\
\hline
\end{tabular}

The analysis determined that in the cases studied, direct revenue from charging is insufficient for a site owner/operator to achieve profitability. In the case of an urban community DCFC complex meeting the minimum requirement, the complex with the lowest break-even cost, profitability would require customers to pay $\$ 0.69$ per kilowatt-hour to charge their vehicles. On a per-mile basis, this is equivalent to paying $\$ 5.91$ per gallon of gasoline in a vehicle that averages $30 \mathrm{mpg}$ (assuming a PEV travels 3.5 miles per kilowatt-hour on average). Similar analysis was performed for a 15 -year payback scenario in which the complex was upgraded from minimum capability without ES and PV to maximum capability with ES and PV after 5 years, and the results are shown in Table ES-4.

Table ES-4. End-user costs required for DCFC complex to financially break even after 15 years, including an upgrade from minimum to ultimate capability after 5 years.

\begin{tabular}{|c|c|c|}
\hline Customer Cost Metric & $\begin{array}{c}\text { Corridor with } \\
\text { Upgrade }\end{array}$ & $\begin{array}{c}\text { Community with } \\
\text { Upgrade }\end{array}$ \\
\hline Electricity Cost $(\$ / \mathrm{kWh})$ & $\$ 0.74$ & $\$ 0.75$ \\
\hline Equivalent Gasoline Cost $(\$ / \mathrm{gal})$ & $\$ 6.34$ & $\$ 6.42$ \\
\hline
\end{tabular}

In the 15 year scenario, the break-even charging costs are similar, but slightly less than, those of the 10-year ultimate capability scenario. It is unknown at this time how much of a premium PEV drivers will be willing to pay for fast charging, but it is expected that this cost would be too high for the majority of 
PEV drivers. This finding suggests that significant investments from public and/or private partners may be necessary. The expectation of lower charging demand in rural areas makes the business case for rural fast charging complexes even more difficult. However, note that the business case analysis is highly sensitive to assumptions for customer utilization. Utilization assumptions made in this case study were purposefully simplified to expedite development of rough cost estimates. Prior to forming firm conclusions or performing further detailed financial analysis, more work is needed to better understand potential customer utilization at individual stations and across entire charging networks. Also, DCFC complex design should be optimized using advanced optimization tools to thoroughly explore the design space and to understand the lowest-cost designs that meet customer needs. 


\section{CONTENTS}

EXECUTIVE SUMMARY

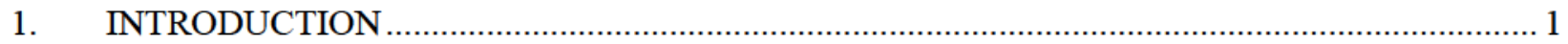

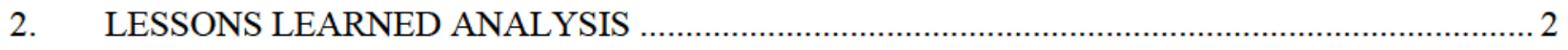

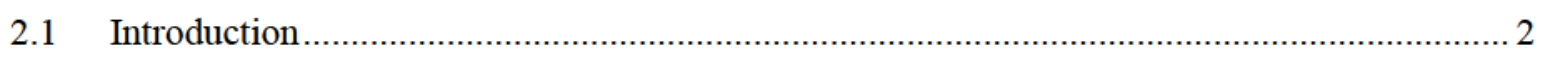

2.2 Direct Current Fast Charging Locations …................................................................ 2

2.2.1 Direct Current Fast Charger Locations in Metropolitan Areas .................................... 4

2.2.2 Direct Current Fast Charger Locations along Commuter and Transportation

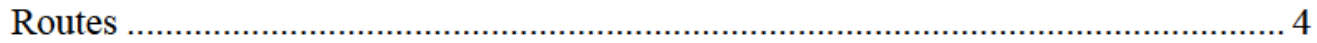

2.3 Direct Current Fast Charger Station Utilization.............................................................. 5

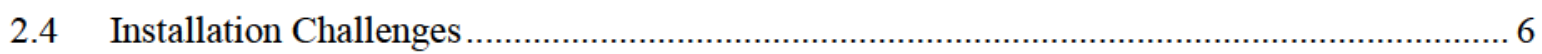

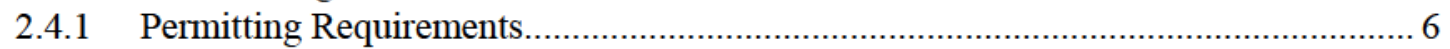

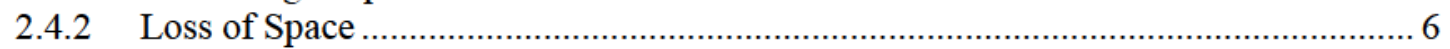

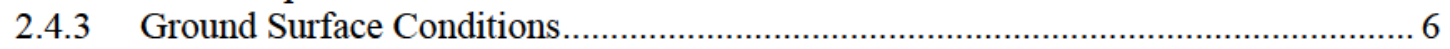

2.4.4 Acquiring Electrical Service ….................................................................... 7

2.4.5 Americans with Disability Act Compliance …...................................................... 7

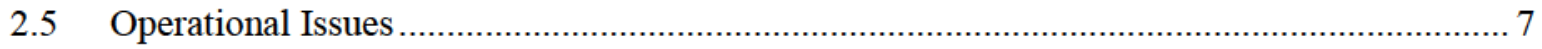

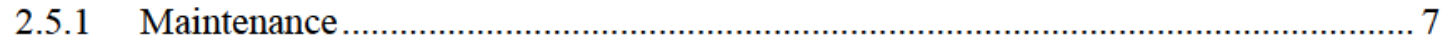

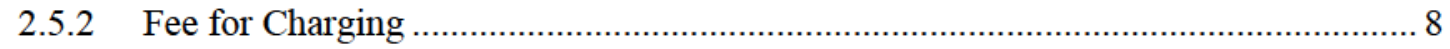

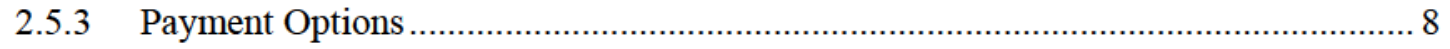

2.6 Direct Current Fast Charger Placement Effect on Plug-In Electric Vehicle Sales................. 9

2.7 Potential for Return on Investment for Direct Current Fast Chargers ................................ 11

3. SITING AND DESIGN CRITERIA FOR COMMUNITY AND CORRIDOR DIRECT

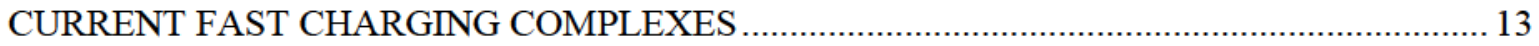

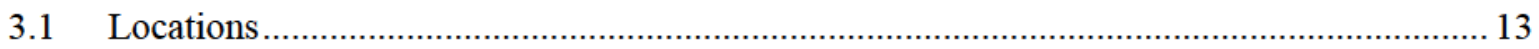

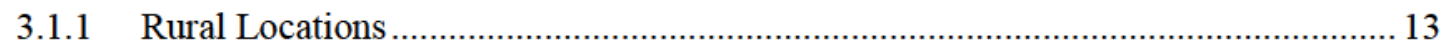

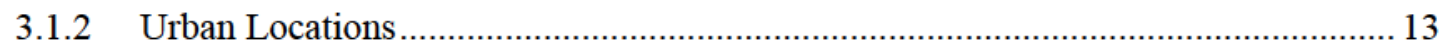

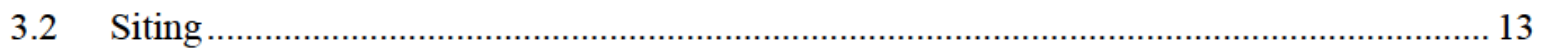

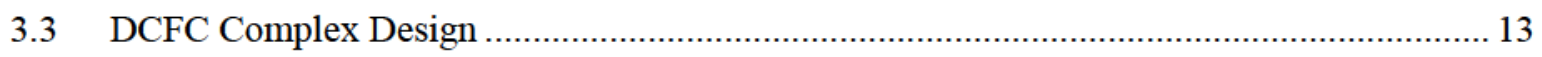

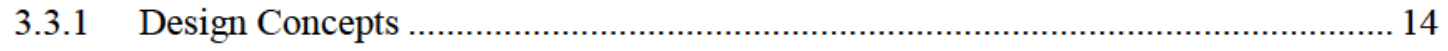

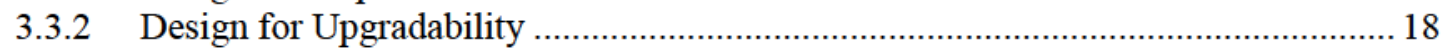

3.4 Direct Current Fast Charger Equipment ……........................................................... 20

3.5 Power/Energy Demand and Grid Impact .................................................................. 21

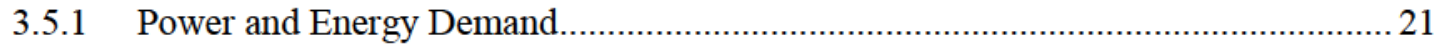

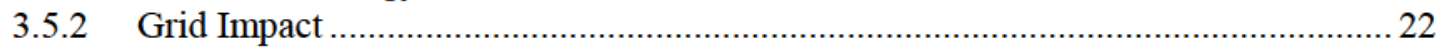

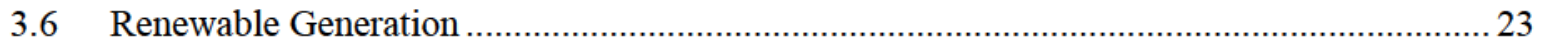

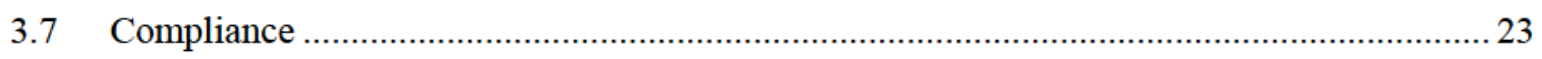

4. SYSTEM SPECIFICATION AND ROUGH-ORDER-OF-MAGNITUDE COST

ESTIMATE …

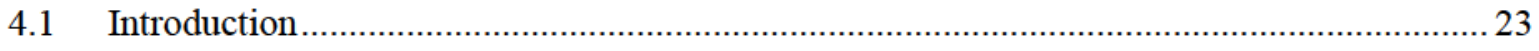

4.2 With Energy Storage and Photovoltaic Energy Systems ……........................................ 24

4.3 Without Energy Storage and Photovoltaic Energy Systems .............................................. 28 


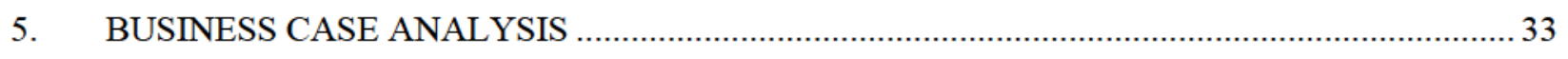

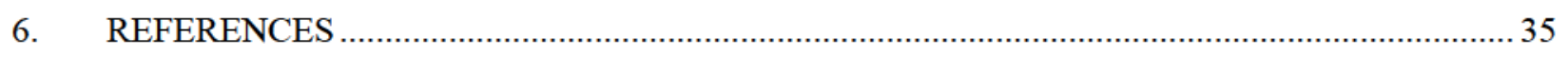

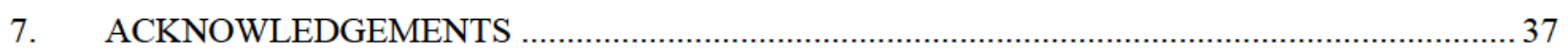

\section{FIGURES}

Figure ES-1. Diagram of a hypothetical multi-port DCFC complex. ...................................................iii

Figure ES-2. Diagram of a multi-port DCFC complex with onsite ES and solar PV systems. .................iv

Figure ES-3. Potential strategy for upgrade from 50-kW complex without ES and PV to $350-\mathrm{kW}$ complex without ES and PV. Magenta highlights in Figure ES-3a show how surface and underground work should be over-built initially to preclude the need for rework upon future upgrade. Figure ES-3b shows the complex upgraded to the future design. $\mathrm{V}$

Figure ES-4. Potential strategy for upgrade from 50-kW complex without ES and PV to $350-\mathrm{kW}$ complex with ES and PV. Magenta highlights in Figure ES-4a show how surface and underground work should be over-built initially to preclude the need for rework upon future upgrade. Figure ES-4b shows the complex upgraded to the future design. .......................vi

Figure 1. Tesla Supercharger stations (source: Tesla) ....................................................................... 3

Figure 2. Deployment of CHAdeMO and CCS-compliant DCFCs (source: DOE Alternative Fuels Data Center).

Figure 3. Share of new PEV registrations in 2015, highlighting leading metropolitan areas in each region (source: ICCT)......

Figure 4. Number of publicly accessible PEV charge ports per million people by metropolitan area (source: ICCT).

Figure 5. Diagram of a hypothetical multi-port DCFC complex......................................................... 14

Figure 6. Diagram of a multi-port DCFC complex with onsite ES and solar PV systems. .15

Figure 7. Potential DCFC complex design variations, showing the relative component size differences representative of current/power and energy capacity ratings.

Figure 8. Potential strategy for upgrade from 50-kW complex without ES and PV to $350-\mathrm{kW}$ complex without ES and PV. Magenta highlights in Figure 8a show how surface and underground work should be over-built initially to preclude the need for rework upon future upgrade. Figure $8 \mathrm{~b}$ shows the complex upgraded to the future design.

Figure 9. Potential strategy for upgrade from 50-kW complex without ES and PV to $350-\mathrm{kW}$ complex with ES and PV. Magenta highlights in Figure 9a show how surface and underground work should be over-built initially to preclude the need for rework upon future upgrade. Figure $9 \mathrm{~b}$ shows the complex upgraded to the future design. 20

Figure 10. Engineering drawing for a hypothetical DCFC complex configuration. .26 


\section{TABLES}

Table ES-1. Summary of approximate costs for DCFC complexes meeting minimum capability requirements. vii

Table ES-2. Summary of approximate costs for DCFC complexes meeting ultimate capability requirements. vii

Table ES-3. End-user costs required for DCFC complex owner-operator to financially break even after 5 or 10 years, assuming revenue comes only from charging fees. viii

Table ES-4. End-user costs required for DCFC complex to financially break even after 15 years, including an upgrade from minimum to ultimate capability after 5 years. viii

Table 1. Net present value of DCFCs across electricity prices and utilization growth rates (source: Coalition for Green Capital).

Table 2. Assumed customer utilization for DCFC complexes with ES and PV systems

Table 3. Community and corridor charging system performance criteria for DCFC complexes with ES and PV systems. 25

Table 4. Capital costs of DCFC complexes with ES and PV systems.

Table 5. Monthly operating costs of DCFC complexes with ES and PV systems. .28

Table 6. Assumed customer utilization for DCFC complexes without ES and PV systems. .29

Table 7. Community and corridor charging system performance criteria and customer utilization assumptions for DCFC complexes without ES and PV systems. 29

Table 8. Capital costs of DCFC complexes without ES or PV systems. .30

Table 10. Summary of approximate costs for DCFC complexes meeting minimum capability requirements.

Table 11. Summary of approximate costs for DCFC complexes meeting ultimate capability requirements.

Table 12. Comparison of installation and upgrade costs for fast charging complexes with and without planning for the upgrade upon initial installation.

Table 13. End-user costs required for DCFC complex owner-operator to financially break even after 5 or 10 years, assuming revenue comes only from charging fees.

Table 14. End-user costs required for DCFC complex to financially break even after 15 years, including an upgrade from minimum to ultimate capability after 5 years. 


\section{Considerations for Corridor and Community DC Fast Charging Complex System Design}

\section{INTRODUCTION}

Idaho National Laboratory (INL), a U.S. Department of Energy (DOE) national laboratory located in Idaho Falls, Idaho, has been DOE's lead laboratory for field testing of light-duty plug-in electric vehicles (PEVs), charging infrastructure, and other alternative vehicle technologies for 25 years. INL has collected data from more than 17,000 charging stations, documenting efficiencies, charge profiles, and PEV drivers' behaviors when using charging infrastructure.

Based on INL's experience and that of its support staff, DOE requested that INL perform the following tasks:

- Identify pertinent lessons learned from previous direct current fast charger (DCFC) deployment and data collection activities and summarize the experience to date with DCFC systems. Topics include installation challenges, costs, locations, usage factors, operational issues, maintenance requirements, system obsolescence, integrated communication systems, consumer billing approaches, customer satisfaction, standards, and vehicle sales data in relation to DCFC siting locations.

- Establish siting and design criteria for multi-port DCFC complexes located in urban communities and on rural highway corridors.

- Perform a design case study and develop a system specification for hypothetical DCFC complexes in the following two scenarios:

- Rural corridor installations that support inter-city travel, sited either in isolated rest stop environments or at community highway access points where there are existing services or commercial businesses

- Urban community installations that support both intra and inter-city travel, located in metropolitan areas at commercial facilities.

The case study includes considerations for land use, signage, power, lighting, current and projected (50 to $350-\mathrm{kW}$ ) DCFC equipment technology, integration, interoperability, communication, construction, maintenance, and warranty issues.

- Develop a rough-order-of-magnitude cost estimate for urban and rural DCFC complexes with and without energy storage (ES) and photovoltaic (PV) energy systems. Cost estimates include the cost to plan, purchase, install, operate, and manage DCFC complexes in these two unique settings.

The purpose of this document is not to develop a single definitive design for all DCFC complexes. Instead, this document will establish general design criteria and then define several simplifying assumptions to facilitate a rough-order-of-magnitude cost estimate. Actual design and cost of DCFC complexes will vary according to local conditions (e.g., customer demand for charging, availability of existing electrical infrastructure, etc.). Evidence of the need for local design variations can be seen in the way Tesla Motors has deployed its Supercharger DCFC network. The number of charge ports at individual Supercharger sites varies from four to 20 charge ports per site [1].

In addition to INL's development of the rough-order-of-magnitude cost estimate, Atlas Public Policy was tasked with identifying business model challenges for DCFC complexes. The results of the Atlas work are summarized in Section 5 of this report and are presented in their entirety in a separate report. 


\section{LESSONS LEARNED ANALYSIS}

\subsection{Introduction}

Since the introduction of publicly accessible DCFC during The EV Project in 2011, DOE and others have conducted studies and surveys on deployment and use of DCFC equipment. This section of the report discusses some of the findings and lessons learned from these studies and surveys that may be used to inform the design of higher-output fast chargers for longer-range vehicles of the future.

The EV Project deployed over 100 DCFC that used the CHAdeMO charging standard. This option for fast charge capability was included on all Nissan Leaf vehicles enrolled in The EV Project. The CHAdeMO standard was adopted by Japanese automakers, whereas U.S. and European automakers have selected the Society of Automotive Engineers J1772 combined charging standard (CCS) for DCFC. Battery electric vehicle manufacturer Tesla developed a proprietary fast charging connector and communications protocol for its vehicles and Supercharger network. Tesla vehicles are not directly compatible with CHAdeMO or CCS-compliant charge port technology. However, Tesla produces an adapter for the CHAdeMO connector, allowing Tesla drivers to charge using CHAdeMO-compliant DCFCs. As a result, Tesla vehicles may charge at most DCFC stations, but non-Tesla vehicles cannot charge at Supercharger stations.

Deployment and customer usage of these DCFC and the challenges and lessons learned thus far provide insight for continued deployment of DCFC in support of a nationwide emphasis on adoption of PEVs.

\subsection{Direct Current Fast Charging Locations}

Tesla has established a nationwide network of DCFC. As stated by Tesla, "Stations are strategically placed to minimize stops during long distance travel and are conveniently located near restaurants, shopping centers, and WiFi hot spots... and in congested city centers" [2]. A map of the Tesla Superchargers is shown in Figure 1. At the time of this writing, Tesla reported 828 locations with 5,339 Superchargers [3]. The Tesla strategy for deployment along major U.S. freeways between metropolitan areas is evident in Figure 1. Initially, usage of these Superchargers was at no cost to the user; however, this changed to fee-based usage for new Tesla buyers beginning in 2017.

The EV Project installed DCFC in eight states. The project's plan for deployment of these DCFCs included locations within metropolitan areas of The EV Project and locations on transportation corridors between metropolitan areas. The latter were intended to enable Nissan Leaf drivers to extend their travel range and move between metropolitan areas. This was most extensively done in Tennessee, where distinct population centers are separated by miles of highway, primarily passing through rural areas.

In October 2013, the governors of California, Washington, and Oregon, and the Premier of British Columbia, signed an agreement called the "Pacific Coast Action Plan on Climate and Energy," [4] which includes a commitment to transition the West Coast to clean modes of transportation. One action is to expand the use of zero-emissions vehicles. In support of this agreement, the states of Washington, Oregon, and California have placed high priority on installation of DCFCs every 25 to 50 miles along Interstate 5 and other major roadways in the Pacific Northwest. Similar promotion of DCFC charging is continuing in some of the states on the East Coast. Figure 2 shows current deployment of DCFCs with CHAdeMO connectors. Most of these locations also provide the CCS connector. Economics and financial return anticipated through usage fees has been a much more important factor in placement of these DCFCs than for the Tesla Supercharger network. 


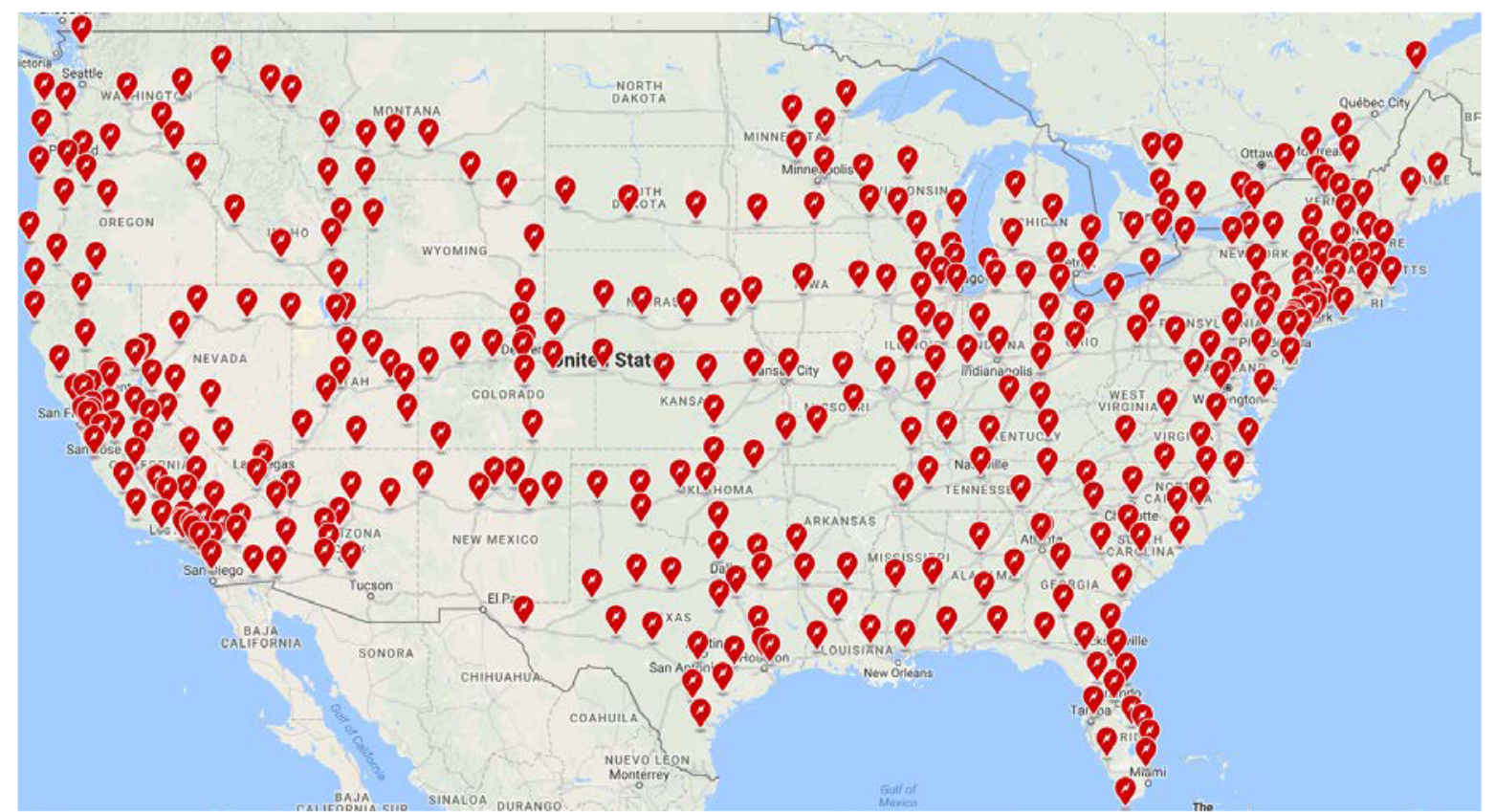

Figure 1. Tesla Supercharger stations (source: Tesla).

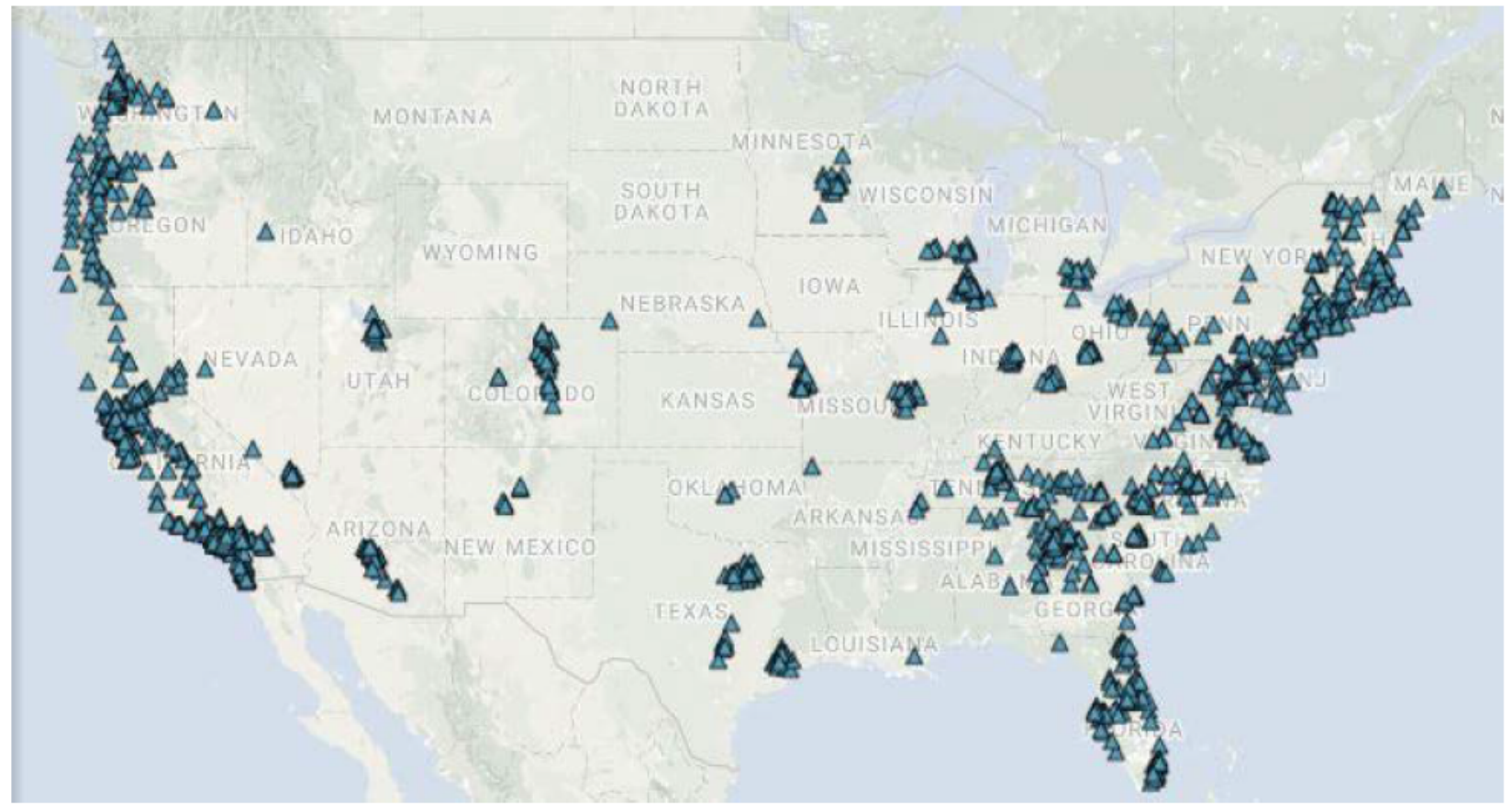

Figure 2. Deployment of CHAdeMO and CCS-compliant DCFCs (source: DOE Alternative Fuels Data Center).

The website for DOE's Alternative Fuels Data Center shows that most DCFC locations with CHAdeMO and CCS connectors are located in major metropolitan areas and, except in a few states, significant work remains to install DCFC along major U.S. interstate corridors. Approximately 1,723 charging stations with 3,126 DCFC offer CHAdeMO and CCS connectors at the time of this writing [5]. 
As part of The EV Project's planning effort, San Diego area planners determined the following should be considered in DCFC site selections:

- DCFC sites should be located along major transportation corridors

- Approximately half of the DCFC sites along a transportation corridor should be located at very high-volume interchanges, with the remaining at slightly lower-volume interchanges

- Characteristics of the host site should be amenable to activities that last between 5 to 25 minutes, which is the typical duration for DCFC sessions (e.g., a coffee shop or convenience store)

- When choosing the spacing of DCFC sites along transportation corridors, planners should keep in mind that current DCFC technology provides up to 80 miles of driving range in 30 minutes of charging [6].

\subsubsection{Direct Current Fast Charger Locations in Metropolitan Areas}

Lessons learned from The EV Project related to installation and utilization of DCFC show that the most highly utilized DCFCs in The EV Project were located in the metropolitan areas of San Francisco (San Francisco was the largest market for Nissan Leaf sales in 2013) and Seattle (Seattle was the fourth largest market for Nissan Leaf sales). A report from The EV Project summarized the relationship between DCFC site location and utilization:

"There is a greater likelihood that a DCFC will be highly utilized if its location exhibits all of the following location-based characteristics:

- Within a half mile of a major commuter route

- On or near the campus of a company with a highly compensated workforce, where it can function as both a workplace DCFC and be publicly accessible

- It is in a welcoming and conspicuous location (i.e., not too closely associated with the host)" [7].

Utilization of DCFC in metropolitan areas continues to grow. The power company NRG Energy reported an increase in use of its EVgo Freedom Stations, which include a DCFC with CHAdeMO and CCS connectors, and an alternating current (AC) Level 2 charger.

"Normalized for growth in the number of Freedom Stations, utilization increased from 6.5 average daily sessions per location in December 2014 to 10.7 average daily sessions per location in December 2015. Furthermore, drivers in a study of 13 Bay Area Freedom 2 Stations that have both DC fast chargers and Level 2 chargers chose DC fast charging by 12:1 over Level 2 chargers" [8].

\subsubsection{Direct Current Fast Charger Locations along Commuter and Transportation Routes}

INL conducted an analysis of use of DCFCs installed in Washington State and Oregon as part of The EV Project and the West Coast Electric Highway Project. The period of study was from September 2012 through December 2013. A total of 68 AeroVironment and Blink DCFC had been installed within 1 mile of Interstate 5 and other highways. Of these 68 DCFC, 57 reported data. Key conclusions from the study were as follows:

- When Nissan Leafs in The EV Project based in Washington and Oregon used DCFCs located inside Seattle and Portland, they tended to use them during round-trip outings of less than 75 miles. This is less than the range of the Leaf on a single charge. 
- Leaf drivers used DCFCs located outside city boundaries to support longer travel, often driving 150 miles or more before returning home. For these drivers, the West Coast Electric Highway successfully enabled significant range extension.

The report provided additional insights on the DCFC network's influence on driving range:

“...When DCFCs were used, drivers covered a much larger geographic area than they did on outings without fast charging.... These results suggest that the West Coast Electric Highway in these areas is being used by EV drivers to support a considerable amount of long distance travel. In fact, further inspection of the data found that there were 19 outings longer than 500 miles. The longest of these outings was 770 miles. To accomplish this, the driver performed 16 fast charges at nine different DCFCs throughout the region" [9].

\subsection{Direct Current Fast Charger Station Utilization}

Several companies have developed and deployed the DCFCs shown in the Figure 2 locations. Some of these stations do not include data reporting capabilities. For others, data are provided to their owners, networks, or hosts, but are not generally available for public analysis. For these reasons, usage statistics of DCFCs are not generally available. However, The EV Project was designed specifically to monitor and report DCFC usage among other activities. The project's final report stated the following:

"DC fast chargers along travel corridors were found to effectively enable longdistance range extension for battery electric vehicles. These chargers were not typically used frequently so their value is hard to quantify from the perspective of the charger host, but when they were used, they provided a vital function to the driver... The project [also] found that public and workplace charging infrastructure enabled drivers to increase their electric driving range, although most drivers did not charge away from home frequently.... For Leaf drivers, charging away from home in areas where DC fast chargers were installed, some chose to only charge using Level 1 or Level 2 charging equipment (63\%), some mixed Level 1, Level 2, and DC fast charging (36\%), and a small number of drivers (1\%) only charged using DC fast chargers" [10].

Considering all DCFC within The EV Project, utilization studies provided the following trends:

- Most fast charging occurred from 4 to 7 p.m., after typical work hours

- Most charges were less than $10 \mathrm{kWh}$

- Half of all DCFC connect events were 20 minutes or less in duration [11].

It should be noted that observations of DCFC utilization to date have been limited to the charging of battery electric vehicles with 100 miles of range or less and may not be directly applicable when projecting utilization by drivers with longer-range electric vehicles.

Because only a few DCFCs in The EV Project were installed in transportation corridors, utilization characteristics for those DCFCs (e.g., time of use and energy per charge) were not separately studied. Additional study of DCFC usage within the West Coast Electric Highway may be desirable. Because these DCFCs were primarily used for range extension, it would be anticipated that charge times would be longer, would vary throughout the day and deliver greater energy.

Note that actual charge acceptance by PEVs like the Nissan Leaf is controlled by the onboard battery management system. Several factors can affect energy acceptance by the Leaf. A report on analysis of data collected from Nissan Leafs enrolled in The EV Project stated "there are a significant number of charge events where the power acceptance (and thus the energy delivered) is well below the maximum $50-\mathrm{kW}$ capability of the Leaf' [12]. For vehicles traveling longer distances, these factors may affect the amount of charge energy actually received. 


\subsection{Installation Challenges}

The decision by charging site hosts to install AC Level 1 and Level 2 charging units, also referred to as electric vehicle supply equipment (EVSE), may be motivated by several factors. This is discussed in a report on the PEV charging station market in New York State:

"EV charging has the potential to earn a premium on the sale of electricity for providing access to charging in public. Given high station utilization, this premium can allow the station owner to recoup its investment and earn a profit.... When the site host owns the charging station, the host [also] receives ancillary benefits such as happier employees and customers and a greener brand image, which could make the investment in charging stations worthwhile, regardless of the return from the sale of electricity. These benefits could make them open to a longer investment horizon than they might be otherwise. As a result, many hosts provide free, subsidized, or at-cost charging" [13].

The cost of DCFC equipment and installation is significantly higher than AC Level 1 and Level 2 EVSE. The higher cost of DCFC presents a significant challenge for potential charging site hosts. In addition, there are several other installation challenges involving installation of DCFC charging stations.

\subsubsection{Permitting Requirements}

Significant changes in a host facility's electrical and physical systems through addition of a DCFC will typically require a permit from local building authorities. More information on permitting DCFC installations was given in an EV Project report on factors influencing the cost to install DCFCs:

"Permit fees varied greatly depending on permitting jurisdiction, extent of construction, whether installation was stand alone or part of another construction project, and whether it was for a new service or just an addition to the existing host electrical system" [14].

These fees have been reported to be as much as $\$ 6,500$ per site. Associated costs for permits are engineering costs to create designs, drawings, and documentation to support permit applications. These costs have ranged from $\$ 1,500$ to $\$ 3,000$ per site [15].

\subsubsection{Loss of Space}

When the DCFC is installed in existing parking lots, the parking spaces adjacent to the DCFC are typically reserved for PEV charging only. Therefore, DCFC installation decreases the availability of parking for vehicles not charging. In some cases, the number of parking spaces required to be reserved for vehicles using charging equipment is determined by local codes. The loss of parking spaces can be a significant factor for some hosts in determining whether they can install the DCFC or other charging equipment.

\subsubsection{Ground Surface Conditions}

The level of effort and cost required to install a DCFC is related to the nature of the surface on which the DCFC will be installed. A report from The EV Project on DCFC installation cost states the following:

"[The cost of] installation of conduit, concrete mounting pads, parking spaces, striping, etc. would vary depending on the surface the DCFC was installed on. Installation of underground electrical conduit was done either by trenching or boring. The basis for this decision depended on the site owners' preference regarding the appearance of the after-work restoration. The decision was also impacted by underground (e.g., water, gas, or electrical services) or aboveground (e.g., planters) features that may have made trenching impractical, and the length of the underground passage" [16]. 
In addition to the ground surface, installation costs increased with distance from the electrical service entry.

\subsubsection{Acquiring Electrical Service}

Today's DCFC typically provides up to $50 \mathrm{~kW}$ of power when charging a vehicle. This is not an insignificant load relative to electrical service at small and medium-sized commercial facilities. Potential DCFC site hosts must determine whether their site has sufficient available electrical capacity to support the power requirements of DCFC(s). A report from The EV Project on DCFC installation cost explained that electrical service was often not available:

"Many of the DCFC installations required new electrical service to be added to the host's site. The cost of these installations was significantly higher than those that did not require new service. The total cost increased due to the fees charged by the local electric utility to extend the service from the grid to the host site and the additional electrical switch gear and new meter required to manage this new electrical service" [17].

In transportation corridors, charging sites sometimes need to be located in sparsely populated areas where existing electrical service is minimal or even non-existent. The cost to establish new electrical service may become a significant barrier for these types of installations.

\subsubsection{Americans with Disability Act Compliance}

Generally, organizations building new facilities or altering existing facilities must comply with the Americans with Disabilities Act (ADA) Standards for Accessible Design. Because DCFC stations offer a service to the public, they must be manufactured and installed to meet the accessibility requirements of federal, state, and local laws. A report prepared for the New York State Research and Development Authority and Transportation Climate Initiative addressed this topic:

"In general, EV drivers spend more time than usual maneuvering around a parking space in order to connect and disconnect from the EVSE. Accessibility strategies should seek to limit tripping hazards and minimize liability concerns.... Wheelchair accessible EV charging needs a free path from the space to the building entrance. Standards are being considered to determine how many, if any, EVSE spaces in a lot should be ADAaccessible" [18].

An EV Project report elaborated further on the subject of designing DCFC and other charging sties for accessibility.

"The ADA Accessibility Guidelines for Buildings and Facilities (ADAAG) does not specifically address charging station design. However, equal access for persons with disabilities to publicly available EV charging stations is still required even absent ADAAG design guidelines. Accessibility to the EVSE and accessibility to the facility are both important, although separate, considerations" [19].

Compliance with ADA is generally determined by the local authority having jurisdiction and is identified during the permitting process. The requirements can vary significantly from jurisdiction to jurisdiction; therefore, they can have an unknown, but potentially significant, effect on DCFC station design and cost.

\subsection{Operational Issues}

\subsubsection{Maintenance}

After installation, some maintenance may be required to keep DCFCs in working order. Data on the maintenance needs of EVSE installed during The EV Project and other past charging infrastructure 
deployment projects were not collected. A report by DOE's Clean Cities Program provides general guidance on EVSE maintenance requirements.

"Typically, there are relatively few EVSE maintenance requirements. In general, the charging cord should be stored securely so it is not damaged, the accessible EVSE parts should be checked periodically for wear, and the system should be kept clean" [20].

In some cases, poor reliability has necessitated repair or replacement of DCFC equipment [21]. In addition to the cost of the repairs, this has driven the need for monitoring of DCFC status, either electronically via a back-haul network or by manual inspection, which adds to the operational cost of a DCFC network. Some PEV charging equipment manufacturers or service providers offer service plans and extended warranties to manage equipment service requirements [22, 23].

\subsubsection{Fee for Charging}

As would be expected, utilization of DCFCs is directly influenced by the fee charged for the service. The EV Project final report described the impact of fees on DCFC utilization:

"Blink DC fast chargers were initially free and usage increased quickly. However, usage dropped dramatically when the Blink Network implemented a usage fee in the summer of 2013" [24].

A report on the PEV charging station market in New York State expounds on different pricing strategies for PEV charging and the potential influence of each on consumer behavior:

"The structure of the pricing plays a big role in incentivizing driver behavior and utilization. Station owners can choose to charge by the kilowatt-hour, by the hour, per session, or some combination of the three. Charging by the kilowatt-hour is the most transparent and straightforward way to charge. However, once a car's battery is full, the car draws very little power, giving the driver little incentive to unplug. One car could end up hogging a charging station all day, blocking the station from use by others. Charging by the hour incentivizes drivers to stay plugged-in for as little time as possible. Charging for the session incentivizes drivers to stay for as long as they would like. Any pricing package that deviates from the straight per-kilowatt-hour rate makes price comparison between home charging, public charging, and gas fueling more difficult. This information gap could deter current EV drivers from charging in public and potential EV drivers from investing in an EV" [25].

DCFC site hosts interested in incentivizing short charging sessions may want to consider a pricing structure with fees based on the time a vehicle spends connected to the DCFC. Billing for the electricity consumed by the vehicle during charging, in terms of kilowatt-hours, is perhaps more intuitive, because today's drivers are accustomed to paying for gasoline by the gallon. However, this method is not feasible in states where regulations prohibit the sale of electricity by anyone other than electric utilities. In areas where it is acceptable, a charging site host may consider a hybrid strategy, where the consumer pays for electricity consumed during charging and time spent connected following the completion of the charge. Another strategy is to have a tiered per-minute rate, where time spent connected after the completion of the charge is more expensive. In any case, the billing method should be clearly identified to the charging site user.

\subsubsection{Payment Options}

Just as there are a variety of DCFC manufacturers, there are several different payment methods. DCFC network providers allow consumers to pay for charging using one or more of the following options:

- Membership card or fob that is linked to the consumer's credit card or subscription account 
- Credit card at the point of sale

- Smart phone app.

In general, an approach that affords consumers universal access to any publicly accessible charging station is preferred. This may be accomplished by integrating credit card readers into DCFC equipment, similar to standard practice for modern gas pumps. However, this approach presents additional issues, such as increased cost, potential for additional maintenance requirements, and a requirement for highly reliable and fast communications.

\subsection{Direct Current Fast Charger Placement Effect on Plug-In Electric Vehicle Sales}

The relationship between public charging infrastructure and PEV sales is a long-held question. Does the availability of publicly accessible charging stations (and specifically DCFCs) increase PEV sales or does public charging infrastructure come as a result of consumer adoption of PEVs? If high utilization of EVSE is desired for financial reasons, it is likely they would be concentrated where there is high availability of PEVs. If encouragement of PEV adoption is desired, it is likely they would be placed where PEV density is low.

The International Council of Clean Transportation (ICCT) performed a study on PEV sales in the United States. Figure 3 shows the leading metropolitan areas for PEV sales by region in 2015, based on PEV registration data collected by IHS Automotive. (Figure 3 was taken from ICCT's report [26].) The West Coast has seen significantly higher PEV adoption than the rest of the country, with the exception of a small number of isolated metropolitan areas.

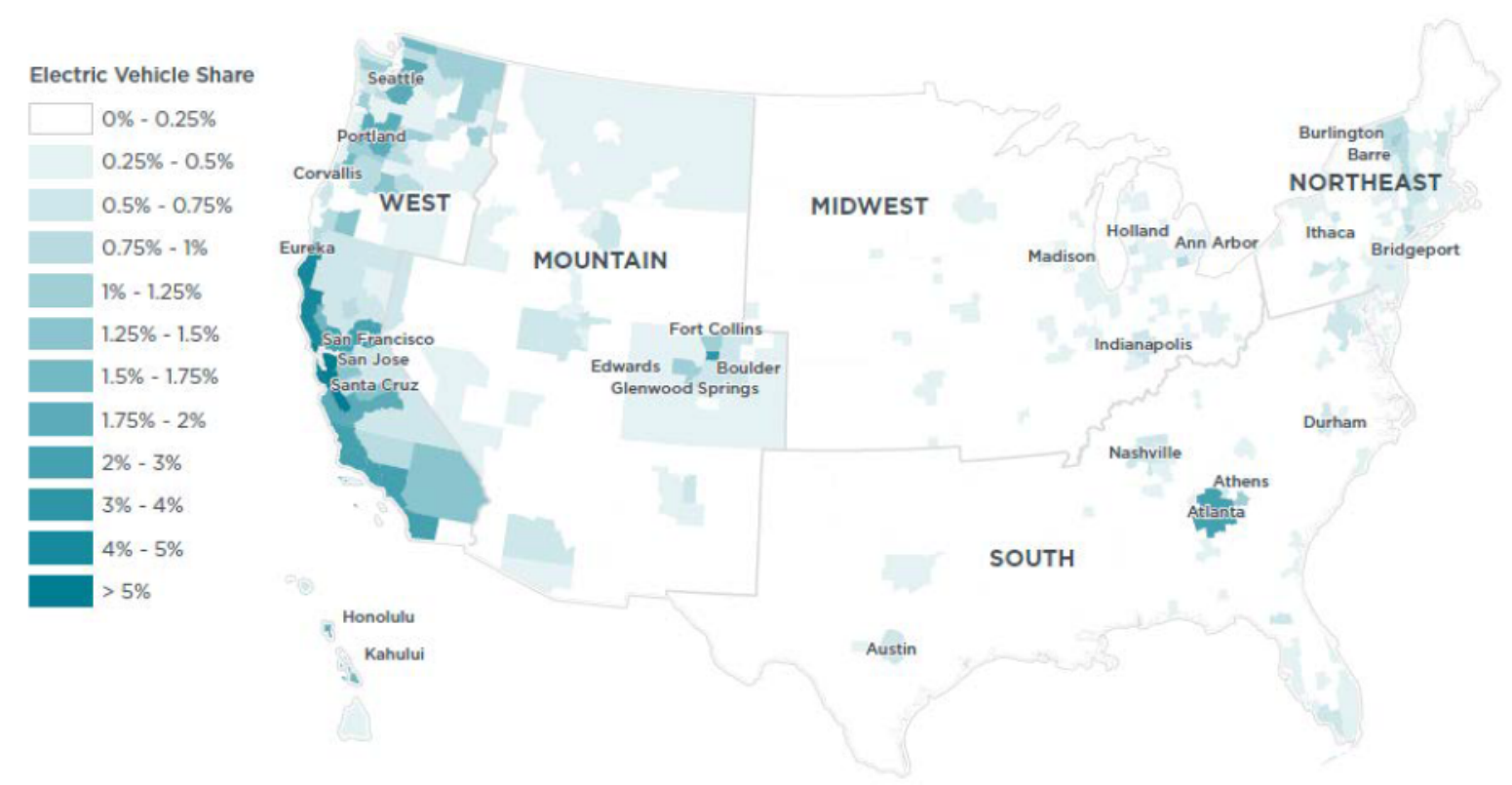

Figure 3. Share of new PEV registrations in 2015, highlighting leading metropolitan areas in each region (source: ICCT).

This study also identified the availability of public charging infrastructure by EVSE type (AC Level 2 and DCFC) in the four to five metropolitan areas in each U.S. region with the highest PEV adoption rates. Figure 4 summarizes these data [27]. ICCT described a correlation between charging infrastructure and PEV adoption: 
“...The West and California had higher average charging availability than the other regions. The regional leaders tended - in 22 of 26 cases - to have greater public charging infrastructure than their regional average. In 13 of the 26 cases, the public charging infrastructure was more than double the national average" [28].

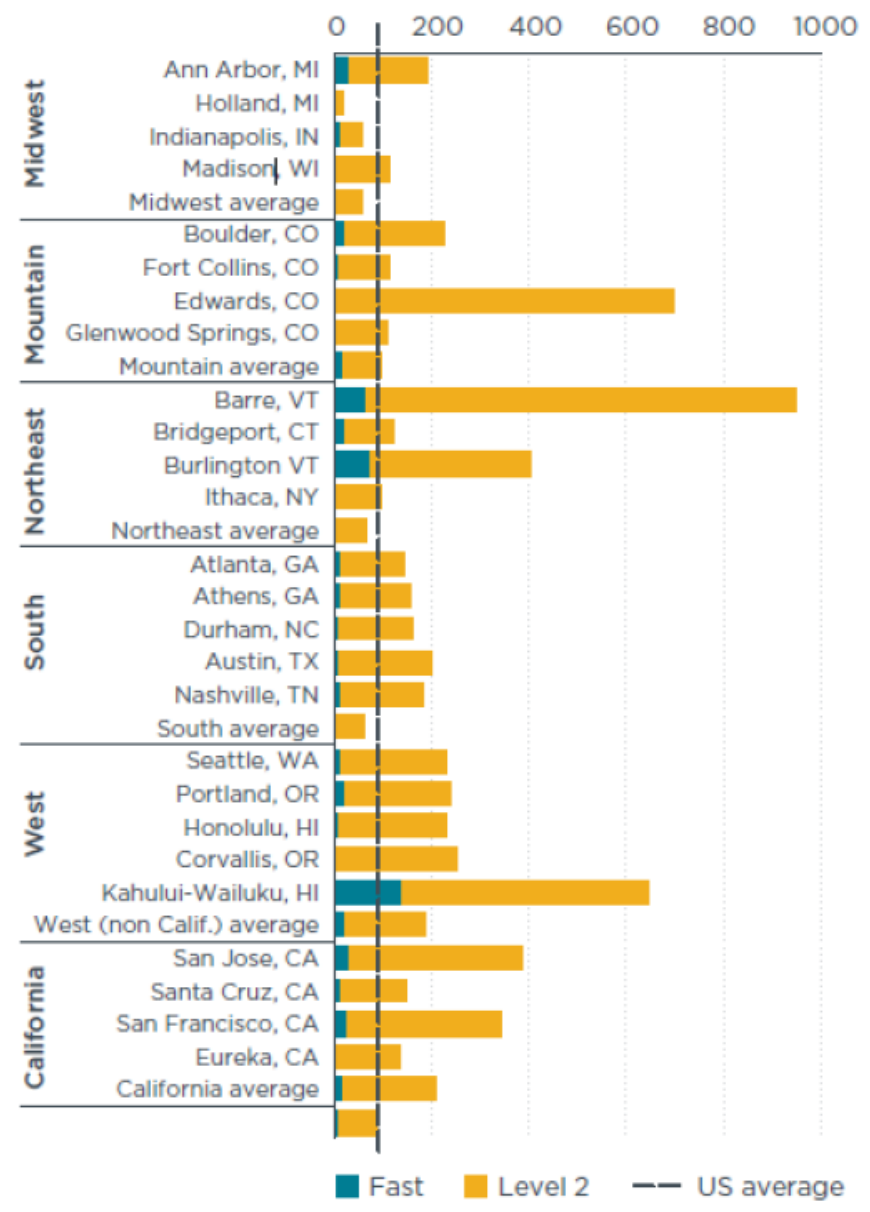

Figure 4. Number of publicly accessible PEV charge ports per million people by metropolitan area (source: ICCT).

The study also identified promotional activities that encourage PEV adoption, such as financial incentives, local fleet programs, and favorable state and local governmental policies. Financial incentives included consumer financial incentives to offset the purchase costs of PEVs, preferential electric utility rates for residential customers owning PEVs, and free high occupancy vehicle lane access for PEVs with single passengers.

ICCT's report on the study made the following conclusion:

"...Generally the areas across the United States that have the highest electric vehicle uptake also have much greater model availability, more extensive public charging networks, and more state and local policy actions to support the market" [29].

While a correlation may exist between metropolitan areas with the highest PEV uptake and the extent to which public charging infrastructure is available, causality is not obvious. Also, Figure 4 shows that few or no DCFCs are available in many of the metropolitan area leading in PEV adoption. Given the immaturity and heterogeneity of the PEV market, further study is warranted before drawing conclusions about the degree to which charging infrastructure availability influences PEV market acceptance. 


\subsection{Potential for Return on Investment for Direct Current Fast Chargers}

DCFC installation costs vary widely. For example, the cost to install about 100 DCFCs in numerous cities across the United States varied from $\$ 8,500$ to over $\$ 50,000$, with a median cost of $\$ 22,626[30]$. These costs did not include the cost of purchasing the DCFC units. Given the high upfront cost of DCFCs, analysis has been performed to determine whether it is reasonable to expect a return on investment. The Center for Climate and Energy Solutions performed one such analysis and concluded the following:

"Private investment in public charging stations is typically not profitable under current market conditions, as the revenues earned from offering public charging services do not offset the costs of purchasing, installing, and operating the stations within a typically attractive payback period of 5 years" [31].

The Coalition for Green Capital performed a similar analysis, as documented in a report on the PEV charging station market in New York State.

"The [net present value (NPV)] of a DCFC is very negative, and reaching a break even NPV is extremely difficult within the bounds of plausible modeling assumptions. This negative economic impact is driven by the increased cost of equipment and installation (assumed to be $\$ 50,000$ ) and the placements of demand charges.... Even if the price is raised to $\$ 1.00 / \mathrm{kWh}, \mathrm{NPV}$ is [only] $\$ 38,744$. Alternatively, keeping the price fixed at $\$ 0.75 / \mathrm{kWh}$, but assuming $20 \%$ annual utilization growth, brings the NPV slightly above zero at $\$ 9,117$. Although this calculation demonstrates the poor economics of a stand-alone DCFC, the analysis does highlight the impact that utilization has on the quality of investment" [32].

In this analysis, the per-kWh price cited is the cost that consumers would pay for charging. The analysis assumes that fees for charging are the only revenue that the DCFC station owner would earn. Table 1 is taken from the report and summarizes DCFC NPV with changing assumptions for charging fees and DCFC utilization.

Table 1. Net present value of DCFCs across charging prices and utilization growth rates (source: Coalition for Green Capital).

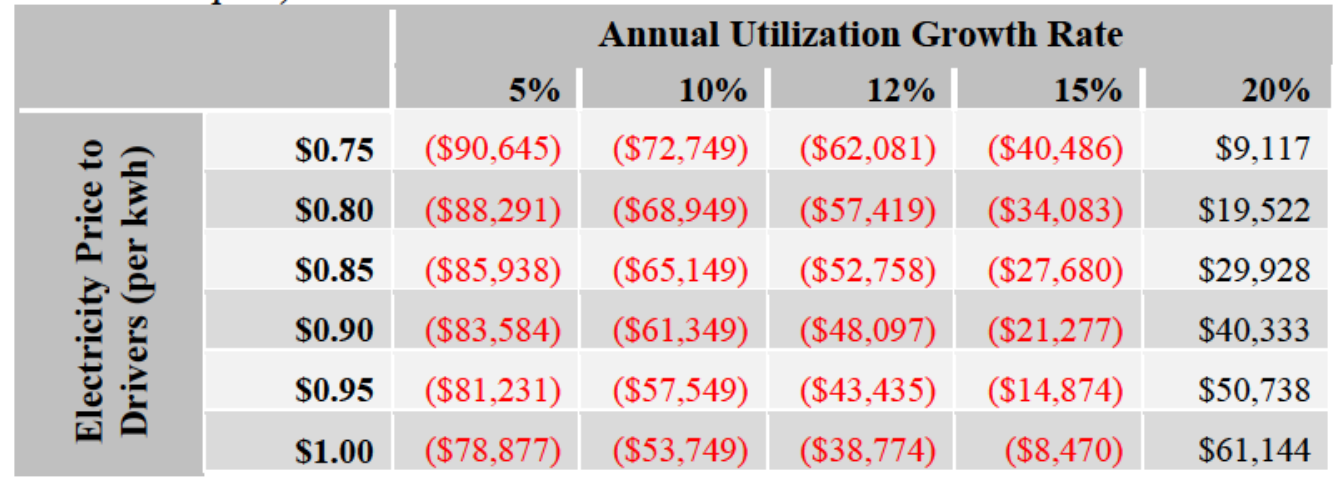

Currently, there are numerous pricing models for DC fast charging offered by many charging network service providers. Fees are levied per session, per kWh charged, per minute, and/or on a monthly basis. Some DCFCs offer free charging. For some charging networks, pricing is uniform from station to station. For others, the local site host can choose the fee amount and/or pricing structure, so pricing varies. Finally, some automakers have created incentive programs in partnership with charging service providers (or the automaker is the charging service provider, in the case of Tesla). In these programs, charging is 
free to the consumer for a period of time after vehicle purchase, such as two years. The automaker presumably covers the cost of charging in these programs.

Considering the wide variation in pricing schemes in today's market, it is difficult to determine a simple national average per-kWh cost to compare to the per-kWh cost benchmarks used in the analysis by the Coalition for Green Capital. However, it is possible to conduct a brief market survey to understand the range of costs for DC fast charging.

The Blink Network charges $\$ 0.49 / \mathrm{kWh}$ to $\$ 0.69 / \mathrm{kWh}$ for $50-\mathrm{kW}$ DC fast charging in four states. In all other U.S. states, fees are $\$ 6.99 /$ session for members and $\$ 9.99 /$ session for non-members. Assuming an average of $8.5 \mathrm{kWh}$ per charge session, ${ }^{1}$ this translates to $\$ 0.82 / \mathrm{kWh}$ and $\$ 1.18 / \mathrm{kWh}$, respectively [33].

A random survey of 24-kW and 50-kW DC fast charging stations on ChargePoint's online station map found wide variation in pricing from site to site. Many DCFCs are free. Some have fees of $\$ 0.15 / \mathrm{kWh}$ to $\$ 0.29 / \mathrm{kWh}$. Others charge $\$ 0.15 / \mathrm{min}$ to $\$ 0.18 / \mathrm{min}$, which equate to $\$ 0.42 / \mathrm{kWh}$ to $\$ 0.50 / \mathrm{kWh}$, assuming an average session time of 25 minutes [34].

AeroVironment offers two pricing models for its 50-kW DCFCs on the West Coast Electric Highway: $\$ 19.99 /$ month or $\$ 7.50$ per session [35]. The latter equates to $\$ 0.74 / \mathrm{kWh}$, using an average energy per session of $10.1 \mathrm{kWh} .^{2}$ If a driver pays the monthly fee and charges 5 times per month, consuming an average of $10.1 \mathrm{kWh}$ per charge, this equates to $\$ 0.40 / \mathrm{kWh}$. The per-kWh cost goes down with additional charging.

EVgo offers options of $\$ 4.95 /$ session plus $\$ 0.20 / \mathrm{min}$ or $\$ 0.10 / \mathrm{min}$ with a $\$ 14.95 /$ month subscription for its 50-kW DCFCs [36]. Without a subscription, consumers will pay the equivalent of $\$ 1.11 / \mathrm{kWh}$, assuming $9 \mathrm{kWh}$ and 25 minutes per charge session. With the subscription, charging 5 times per month results in an average cost of $\$ 0.61 / \mathrm{kWh}$. More frequent charging reduces this cost.

Available data is not sufficient to determine the relative popularity of the different pricing models, so it is not possible to determine an average cost that consumers are willing to pay. Additionally, the availability of no-cost-to-consumer charging programs, such as BMW / ChargeNow by EVgo, Nissan No Charge to Charge, and Ford EV 1-2-3 Charge programs make it impossible to determine how many DCFC customers are actually paying anything for charging. Nevertheless, based on the review of available options, it is reasonable to assume that a large fraction of DCFC customers average between $\$ 0$ and $\$ 0.74 / \mathrm{kWh}$ to use today's DCFCs.

In conclusion, direct revenues from the collection of fees for usage do not outweigh the costs associated with procurement, installation, and operation of DCFCs unless fees are elevated (which discourages use), utilization is high (which requires a high population of PEV users), or incentives are applied (which decreases equipment costs, installation costs, or both). Indirect revenue related to increased customer traffic in adjacent businesses, increased stay time by customers, advertising space on the equipment, or creation of a "green" image may reduce the gap. In some cases, PEV manufacturers contribute to the costs, presumably because they believe charging stations may lead to additional sales or support other goals. In some cases, nearby businesses may contribute to the charging station host's cost if they see potential indirect revenue. Favorable conditions are more probable in metropolitan areas rather than along transportation corridors, where utilization may be especially low. In these areas, greater emphasis on grants or other outside funding may be necessary.

\footnotetext{
${ }^{1}$ Blink DCFCs averaged $8.5 \mathrm{kWh}$ and 20 minutes per charge in 2015 , according to unpublished INL analysis of data provided by CarCharging Group.

${ }^{2}$ AeroVironment DCFCs on the West Coast Electric Highway in Washington and Oregon averaged $10.1 \mathrm{kWh}$ and 30 minutes per charge in 2015, according to unpublished INL analysis of data provided by AeroVironment.
} 


\section{SITING AND DESIGN CRITERIA FOR COMMUNITY AND CORRIDOR DIRECT CURRENT FAST CHARGING COMPLEXES}

To meet the needs of existing and future PEV drivers seeking convenient fast charging, planners should consider the design criteria for the charging complex provided in the following subsections.

\subsection{Locations}

For the purpose of this study, DCFC complexes may be located in either rural corridors or urban communities.

\subsubsection{Rural Locations}

A DCFC network that enables regional and nationwide travel would require DCFC complexes to be built in rural locations to support inter-urban travel. These complexes likely would be located between urban centers and would typically be associated with other travel corridor facilities (e.g., truck stops, fast food, convenience stores, and tourist information centers). A rural DCFC complex is expected to have fewer overall charge events, but transfer more energy per charge event than urban DCFC complexes.

\subsubsection{Urban Locations}

A DCFC complex in an urban location would be expected to serve three types of customers: (1) the intra-urban traveler seeking a "top off" charge to continue their day's activities, (2) PEV owners who do not have regular overnight charging opportunities (e.g., residents of multi-unit dwellings), and (3) the inter-urban traveler passing through or arriving in an urban area on the way to their final destination.

Urban community complexes likely will have more frequent charge events than rural locations. For maximum PEV driver convenience, they should be sited near commuting travel corridors within a metropolitan area. Because urban charging complexes will be used to support a variety of travel needs, the energy transferred will vary from "top off" charges to full charges.

\subsection{Siting}

The specific site for a DCFC complex will vary depending on available space, whether onsite energy storage or generation is included, and whether the location is in a rural or urban environment. Siting criteria for the two types of DCFC complex locations are as follows:

- Rural

- Direct access to/from a state or federal highway (e.g., less than 1,000 ft)

- Nearby access to grid power

- Associated with other entities (e.g., convenience stores, truck stops, restaurants, or points of interest).

- Urban

- Adjacent to high-traffic streets and commuter routes

- Nearby access to grid power

- Direct access should exist for site ingress and egress to street from both directions.

\subsection{DCFC Complex Design}

The equipment installed at a charging complex must be able to support the needs of the existing population of PEVs, but also must be prepared to support future ultra-fast charging capabilities. 


\subsubsection{Design Concepts}

A DCFC complex representing current technology and without onsite energy storage or generation would typically include the components shown in Figure 5.

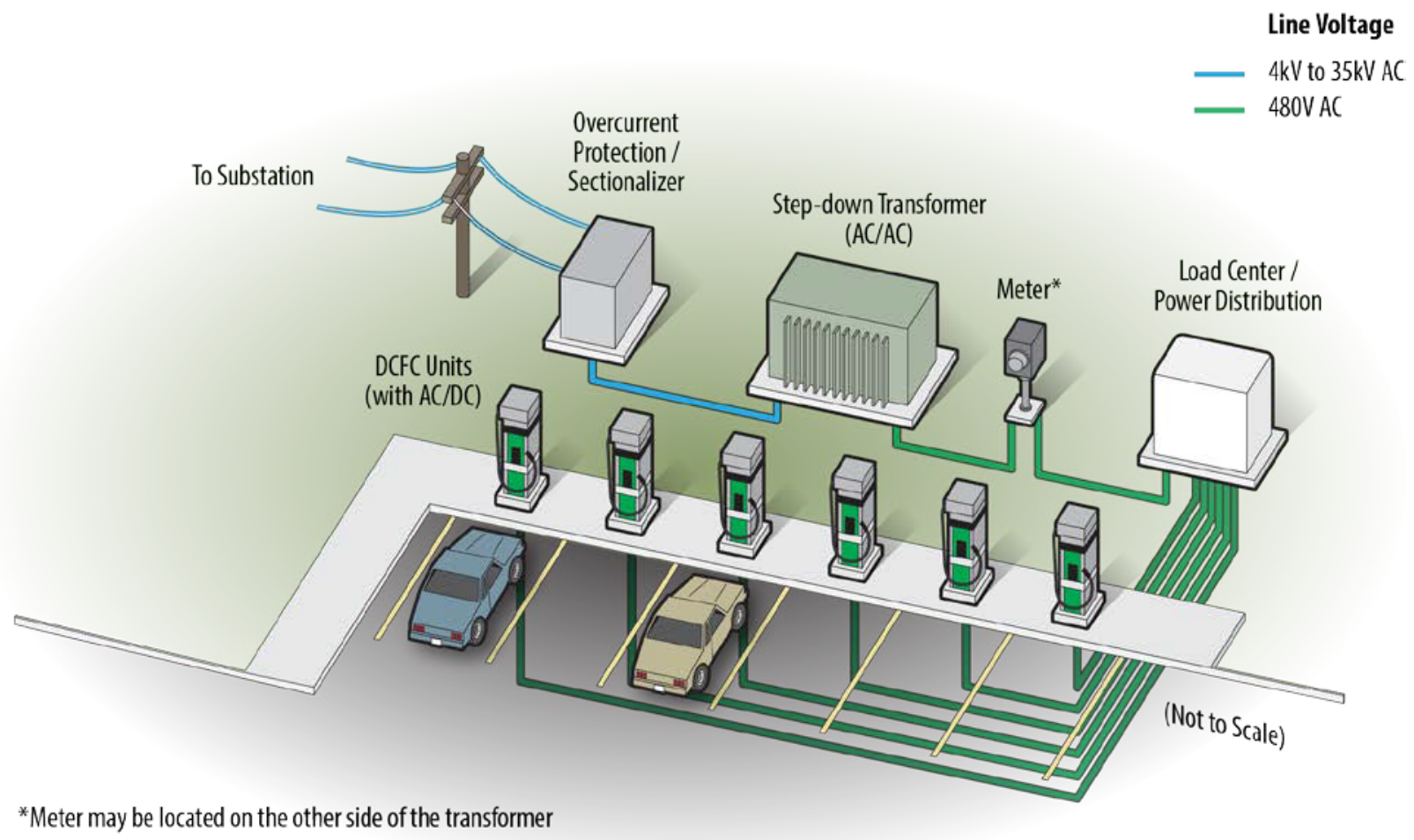

Figure 5. Diagram of a hypothetical multi-port DCFC complex.

In this design, each DCFC unit is supplied with 480 VAC. A step-down transformer, which decreases voltage from the distribution voltage to the $480 \mathrm{VAC}$ required by the chargers, is typically located onsite. If the electric utility owns the transformer, then the meter is positioned downstream of the transformer, as shown in Figure 5. If the complex owner owns the transformer, then the meter is located on the grid side of the transformer. Ownership policies vary by utility and may need to be negotiated on a site-by-site basis. The electric utility employs a high-voltage overcurrent protection device (e.g., fuse or circuit breaker) and/or sectionalizer (i.e., circuit-opening device) between the transformer and the distribution feeder, as shown in Figure 5, although this equipment may not be located onsite. The load center contains a circuit breaker panel that provides overcurrent protection and distributes power to the individual DCFC units. AC/DC conversion, charger-to-vehicle communication, user interface, and power delivery are all performed within each DCFC unit. Depending on the design of the DCFC units and the power output requirements, a separate electrical cabinet may be required between the load center and the DCFC units to house power electronics modules necessary for high-power charging. This may be done to minimize the bulk of the curbside DCFC units to improve design aesthetics and the user experience and to reduce cost. The complex's electrical equipment, conduit, and conductors are sized based on the power capacity of the complex, which is a function of the rated capacity of each DCFC unit and the number of chargers at the complex. Site design and components that are used may vary according to practices of individual electric utilities and other site-specific factors.

Urban community and rural corridor charging complexes are expected to be designed similarly, with components sized according to differences in expected customer demand for charging. A notable exception is the case of an urban complex in a densely populated city center where space is highly 
constrained. In this case, the transformer and other electrical equipment would likely be housed in an underground vault below or adjacent to the complex.

Currently, maximum DCFC charge rates for individual chargers on the market range from 24 to $145 \mathrm{~kW}$, with the majority of DCFC units rated at 50 or $60 \mathrm{~kW}$. However, as auto manufacturers increase PEV battery size to extend vehicle driving range, DCFC manufacturers have begun developing systems capable of delivering $350 \mathrm{~kW}$ or more to decrease charging time. The capital equipment cost of complexes with DCFCs rated at these high-power levels can be extremely expensive. Operating costs also can be very expensive because electric utility rate structures include a fee for power; this is referred to as a demand charge. One method for managing capital and demand charges is to limit the maximum power drawn from the grid by the entire complex, and then control the distribution of power to individual DCFC units as they charge vehicles so that the aggregate power demand from the grid stays below the established limit. The drawback of this option is that when multiple vehicles charge simultaneously, power may be limited to below the maximum rating of individual DCFC units and/or vehicles, and charge time may increase.

Adding onsite ES and PV generation to a DCFC complex decouples the power provided to vehicles from power drawn from the grid. Generation and storage systems can be sized to allow vehicles to draw high power, while limiting the power drawn from the grid to a set value to limit electricity cost. Provided the ES system is sized appropriately, this allows vehicles to charge at full power and avoids the problem of increased charging time. A diagram for a DCFC complex with this capability is shown in Figure 6 . The meter location and components used may vary by utility or according to other site-specific considerations.

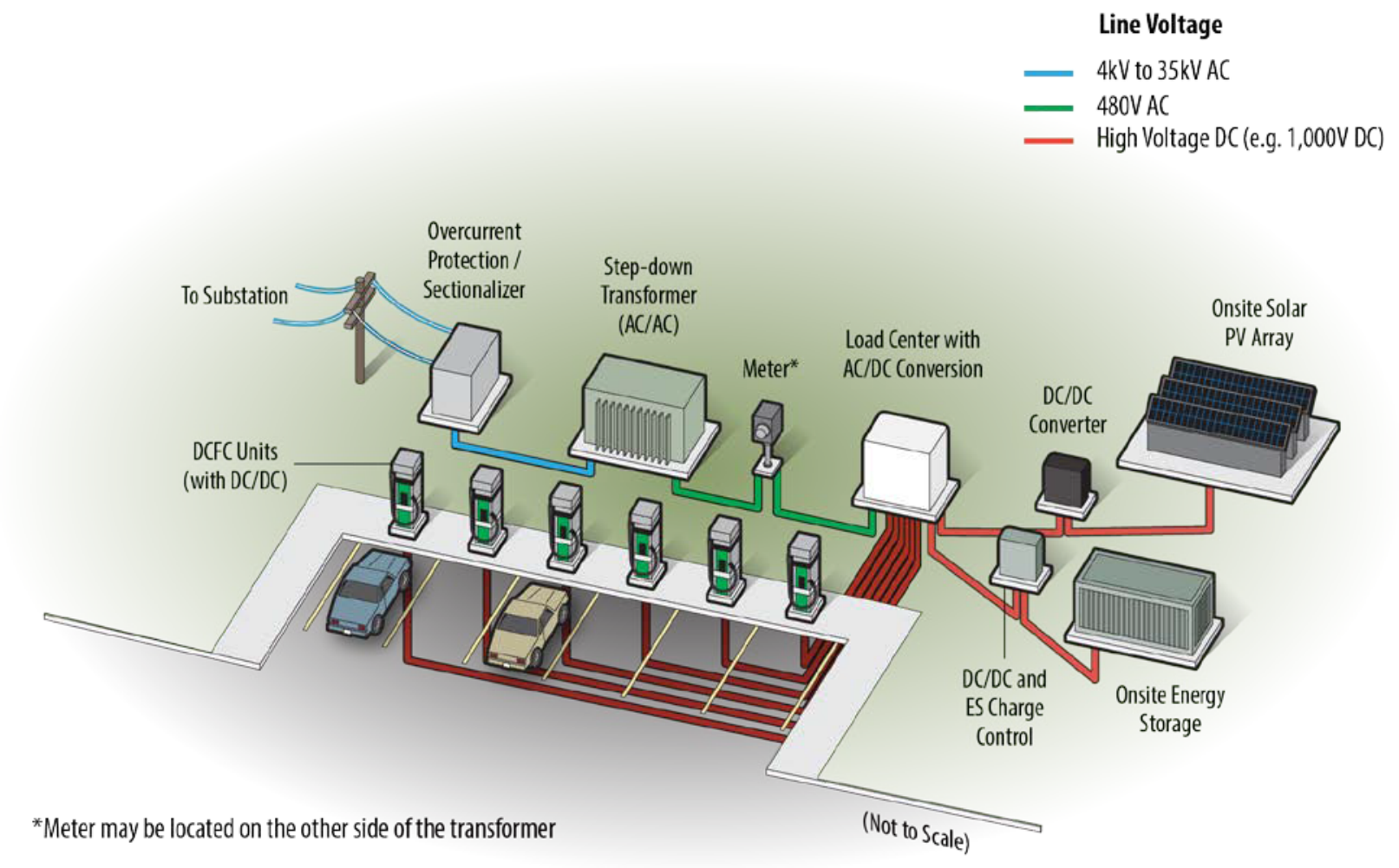

Figure 6. Diagram of a multi-port DCFC complex with onsite ES and solar PV systems.

This system employs a single, high-power AC/DC converter to create a high-voltage DC bus (highlighted in red in Figure 6). The DCFC units, ES system, and a PV solar array are all connected to this high-voltage bus. This decreases the complexity of DCFC units, because each DCFC would only require a DC/DC converter to match the vehicle battery voltage. The connection of other components to 
the system would be simpler for similar reasons. PV arrays and battery ES are both DC systems; therefore, connecting them to a DC bus requires only a DC/DC converter for voltage matching.

The current and power ratings of components in a DCFC complex vary noticeably as desired vehicle charge power level increases and depending on whether or not an ES system is employed. Figure 7 depicts this variation, using physical size as a representation of relative current and power capacity, for DCFC complexes with 50-kW and 350-kW chargers with and without ES and PV systems. As an example, the design configuration in Figure 7a may have a 300-kVA transformer to provide grid power to satisfy the demand of multiple 50-kW chargers. The transformer in Figure $7 \mathrm{~b}$ may have a 1,500-kVA transformer to meet the demand of 350-kW chargers. The design shown in Figure 7c would provide power for charging from the grid, ES system, and PV system, so the transformer could be sized at $150 \mathrm{kVA}$. Finally, the transformer in Figure $7 \mathrm{~d}$ may be sized at $300 \mathrm{kVA}$ for $350-\mathrm{kW}$ charging, because the majority of the power needed for charging would come from the ES system. In reality, the physical size of the components in a DCFC complex increases as current and power ratings increase, but not necessarily at the scale depicted in Figure 7. 


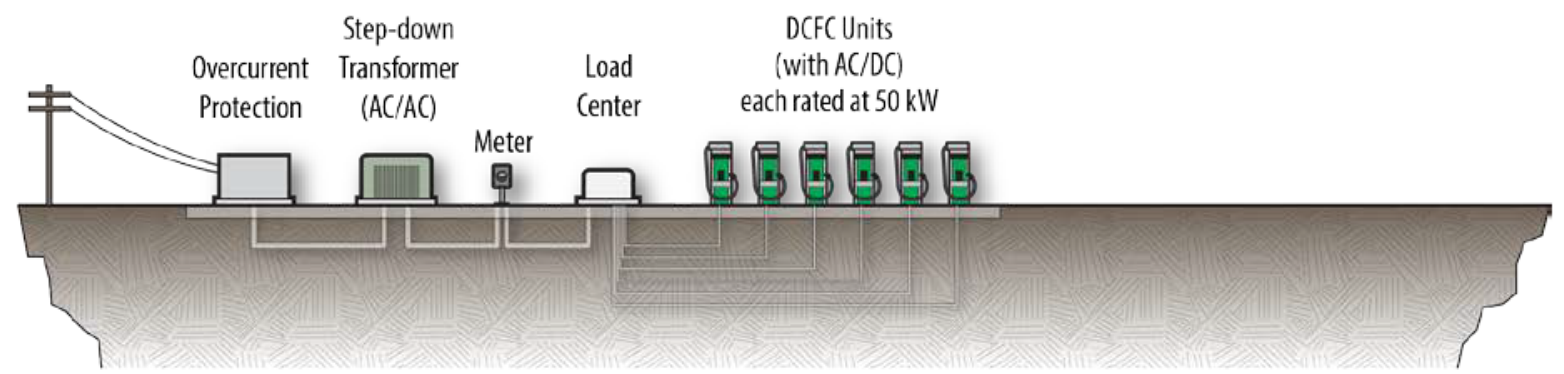

A) DCFC complex with 50-kW chargers and no ES and PV systems

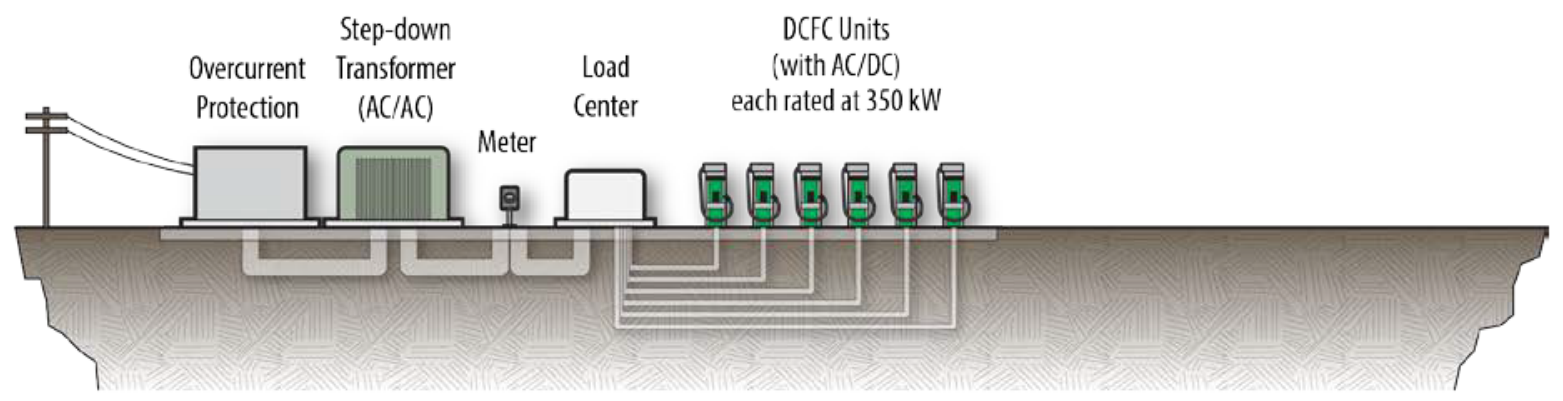

B) DCFC complex with 350-kW chargers and no ES and PV systems

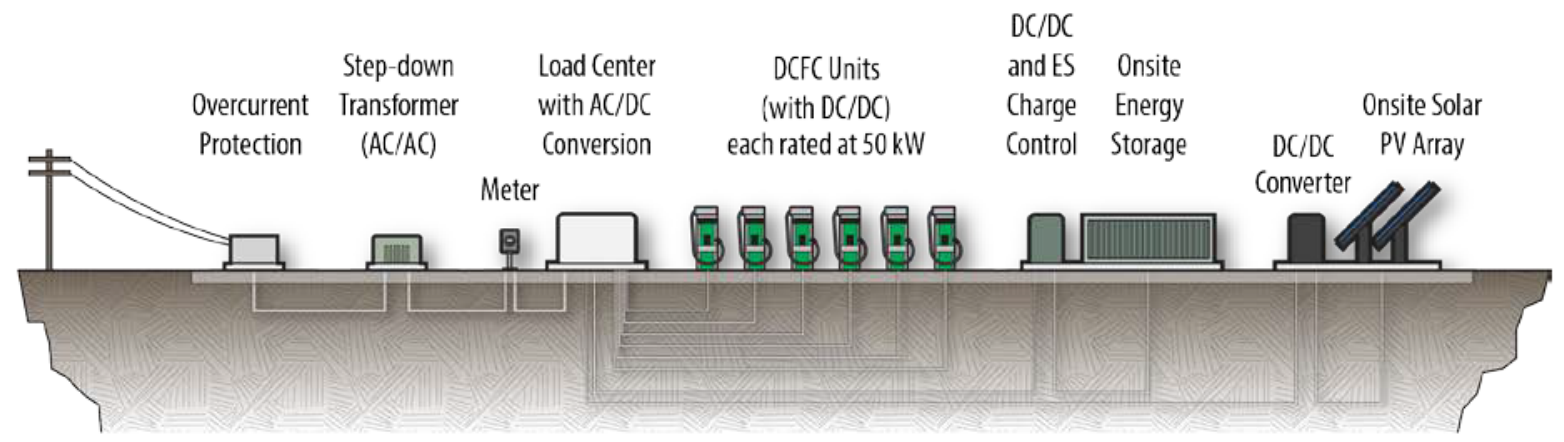

C) DCFC complex with 50-kW chargers and ES and PV systems

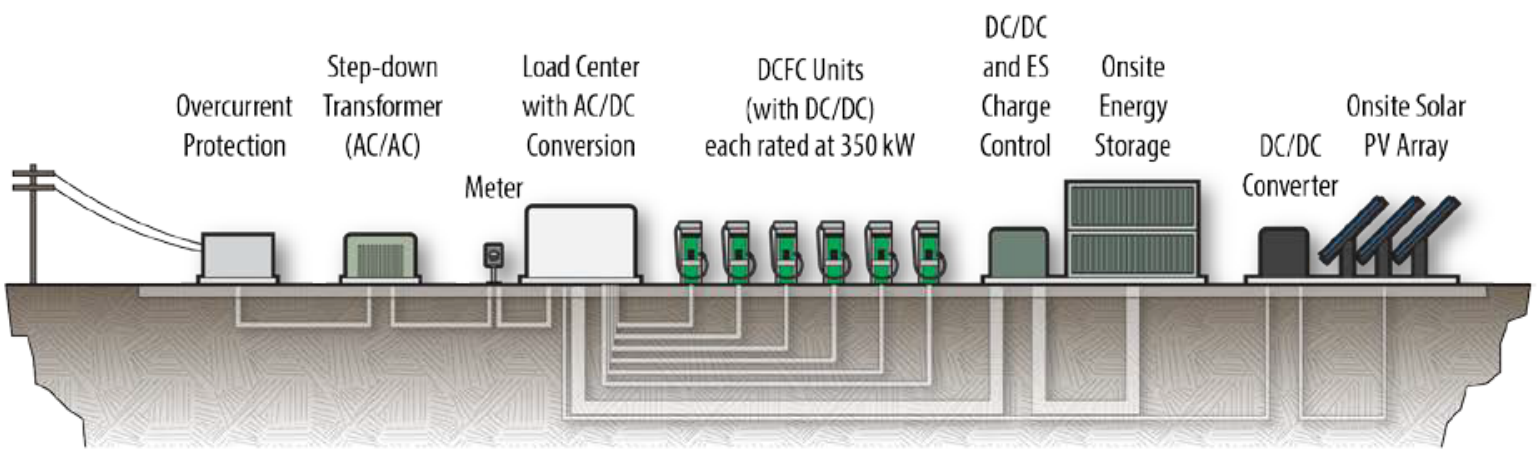

D) DCFC complex with 350-kW chargers and ES and PV systems

Figure 7. Potential DCFC complex design variations, showing the relative component size differences representative of current/power and energy capacity ratings. 


\subsubsection{Design for Upgradability}

In the near term, DCFC complexes should be designed to serve the hundreds of thousands of fastcharge-capable PEVs already on the road. Most of these vehicles can charge at $50 \mathrm{~kW}$ or less. Therefore, it may be tempting for designers to define equipment power requirements to support only $50-\mathrm{kW}$ charging to limit capital costs. However, designing for flexing and upgradability from the beginning may be a more prudent approach. To this end, the DCFC complex should be designed upfront to accommodate increased charge power, which is determined by the site's power supply, DCFC equipment power capability, and numerous other design factors. Because the future market for vehicles capable of high-power charging is uncertain, and because of the high capital cost of DCFC complexes, an upgrade strategy is not without risk. One of the purposes of this report is to elucidate the cost trade-offs of different DCFC complex upgrade strategies.

The first step toward understanding these trade-offs is to determine how the DCFC complex design may change with increasing charge power requirements. When increasing the power capability of the charging complex, several upgrades will be needed, including the following:

- Higher-capacity electrical equipment, such as the step-down transformer, load center, and AC/DC converter

- Larger or additional concrete pads to accommodate larger or new equipment

- Upgraded or new DCFC units

- Conductors with higher current rating

- Larger diameter conduit.

Because of uncertainties in technology development timing and market demand, it may not be cost effective to initially size all DCFC complex components to meet expected future power demands. However, it may make sense for certain portions of the site to be constructed to accommodate future power expansion. Surface and underground work required to construct a DCFC complex (e.g., trenching for conduit, laying concrete pads, and construction of the transformer vault, if applicable) can incur significant cost because it is labor-intensive. During initial installation, conduit that can accommodate future power requirements should be laid to eliminate the need for re-trenching. Also, sizing concrete pads for higher power levels would reduce the cost of the upgrade process and ensure adequate space is reserved for future expansion. Figure 8 illustrates this strategy. Figure 8a depicts a DCFC complex with six DCFC units capable of 50-kW charging, without ES and PV systems. Conduit and concrete pads (highlighted in magenta) are sized during initial complex construction to prepare for a future upgrade to six $350-\mathrm{kW}$ chargers. In this example, all above-ground equipment would be upgraded in the future to support 350-kW charging, as shown in Figure 8b.

If the end goal is to construct a DCFC complex that employs ES and PV systems to minimize the operational cost and grid impact of 350-kW charging, then the complex upgrade strategy should be different. Figure 9 illustrates an upgrade strategy for this case. Again, conduit and concrete pads are oversized initially to avoid rework upon future upgrade, as indicated by magenta highlights in Figure 9a, but sizes vary according to the different current/power ratings necessary for the future design. Also, additional conduit and cable are laid for future installation of ES and PV systems, shown in Figure 9b.

In addition to surface and underground work, above-ground electrical equipment could also be upgraded at the time of initial installation to avoid the need to replace the equipment later. However, note in Figure 8 how the size of the grid-side overcurrent protection device and step-down transformer change dramatically when the complex is upgraded to support 350-kW charging, but they do not change in Figure 9. Appropriate upgrade strategies will vary based on future DCFC complex design requirements; therefore, it is vital to determine the future design of the complex, prior to initial complex construction. 
Otherwise, investment may be wasted by over-building the complex initially with more expensive, higher-capacity components that may never be needed.

In accordance with this conclusion, Sections 4 of this report delves into the cost differences between DCFC complex design configurations to identify the most cost-effective initial and final designs. An appropriate upgrade strategy with the overall cost estimates is presented in Section 4.4.

Sized for Future Upgrade to $350-$ kW DCFC Units

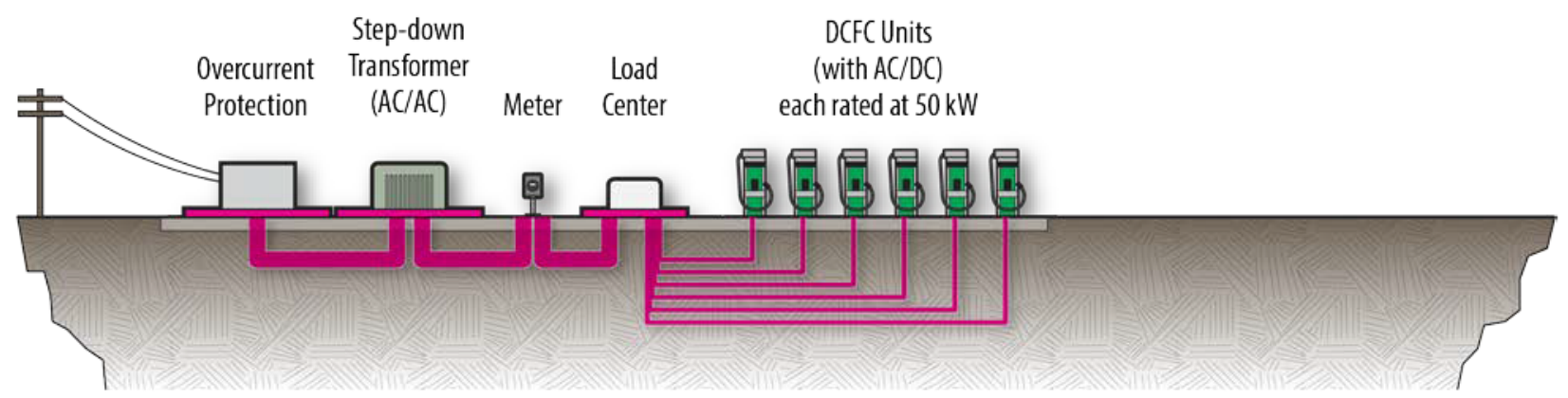

A) DCFC complex with 50-kW chargers and no ES and PV systems

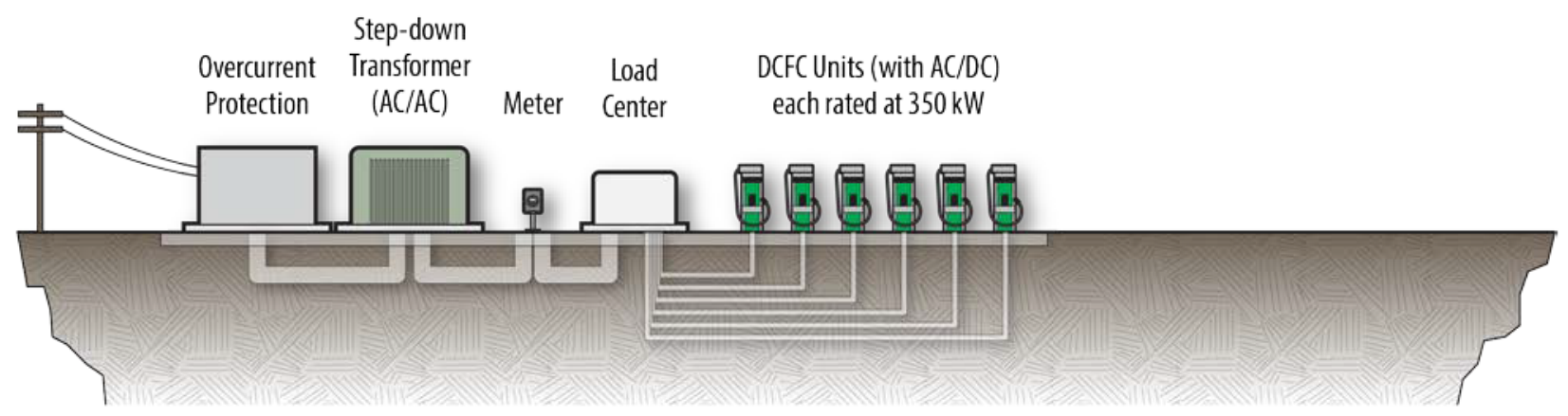

\section{B) DCFC complex with 350-kW chargers and no ES and PV systems}

Figure 8. Potential strategy for upgrade from 50-kW complex without ES and PV to 350-kW complex without ES and PV. Magenta highlights in Figure 8a show how surface and underground work should be over-built initially to preclude the need for rework upon future upgrade. Figure 8b shows the complex upgraded to the future design. 


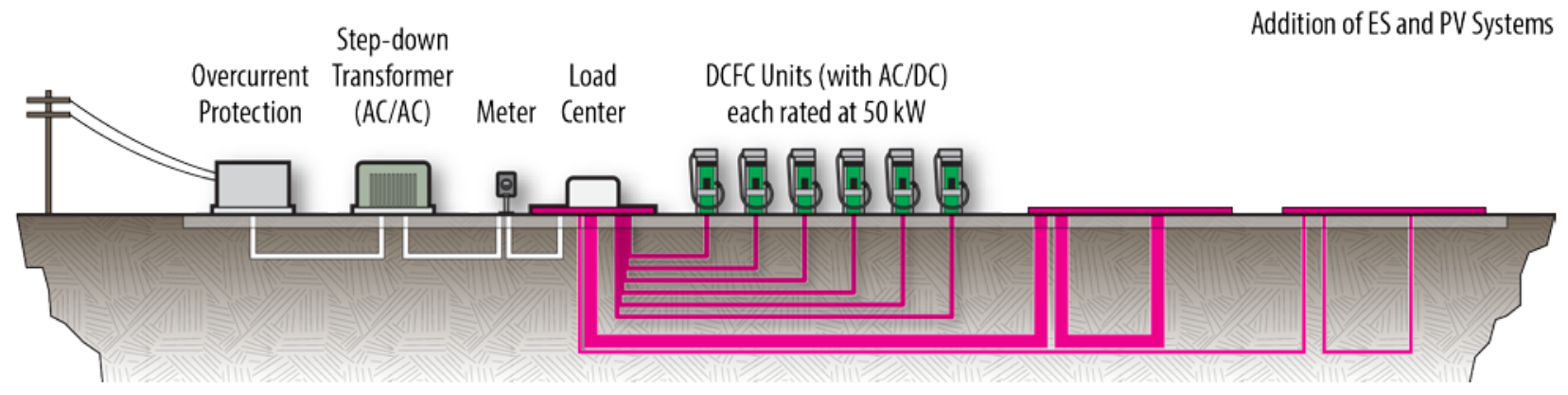

A) DCFC complex with 50-kW chargers and no ES and PV systems at initial installation

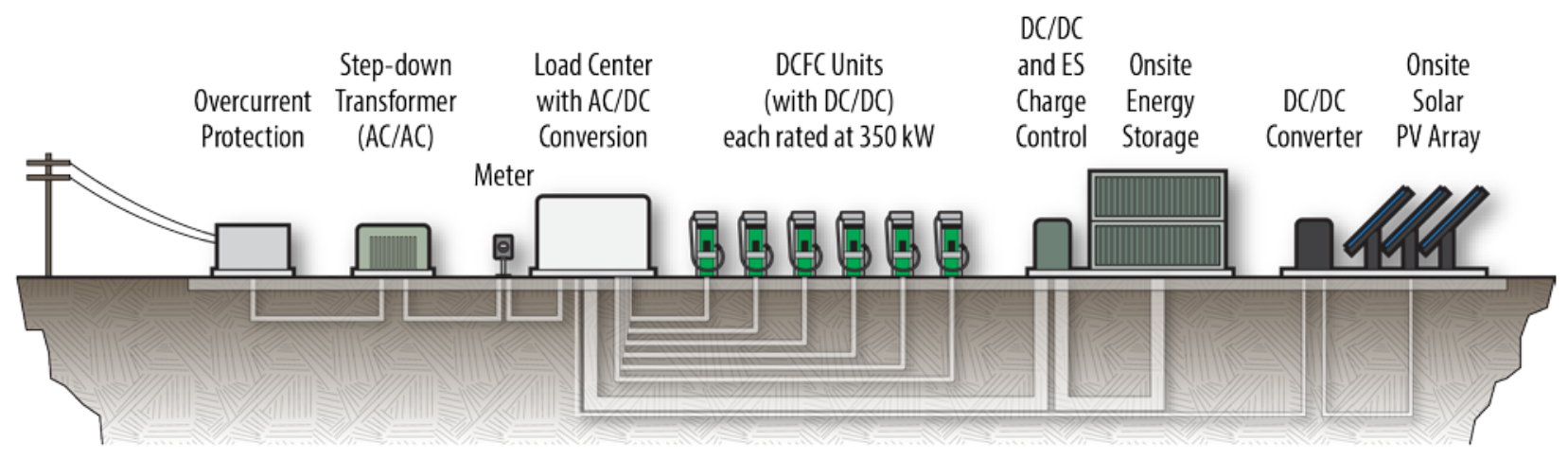

B) DCFC complex with 350-kW chargers and ES and PV systems

Figure 9. Potential strategy for upgrade from 50-kW complex without ES and PV to $350-\mathrm{kW}$ complex with ES and PV. Magenta highlights in Figure 9a show how surface and underground work should be over-built initially to preclude the need for rework upon future upgrade. Figure $9 \mathrm{~b}$ shows the complex upgraded to the future design.

\subsection{Direct Current Fast Charger Equipment}

DCFC equipment should be able to fulfill the needs of all vehicles capable of accepting a fast charge and should have the appropriate charge connector for the market being served (e.g., CHAdeMO, CCS, or future ultra-fast charging standard yet to be determined). DCFC units should be backward-compatible, meaning they are capable of providing the power level demanded by older model vehicles, even if that level is well below the rated power of the DCFC unit.

DCFC equipment should be compatible with the complex's control system that varies power allocation between units when multiple vehicles are charging simultaneously to prevent overall demand from exceeding the site's power capacity. This can be done using various priority algorithms (e.g., first in, first out; lowest state of charge gets the most power; and equal share).

DCFC equipment capable of charging at or above $350 \mathrm{~kW}$ will have unique design features, in comparison to today's $50-\mathrm{kW}$ chargers. Connectors on charge units providing $350 \mathrm{~kW}$ or higher power are expected to have high-tech conductors, liquid cooling, and/or other features to manage heat created by high power and to limit cord girth for ergonomics. With respect to the DCFC unit as a whole, manufacturers may choose a modular design strategy. They may offer a base DCFC model with limited 
power capacity, but design in expansion slots that allow the owner to install additional power electronics modules to increase capacity without needing to replace the DCFC unit.

The requirements for high-power DCFC units may evolve as automakers bring PEVs capable of charging at higher power to market. It is expected that DCFC manufacturers and network service providers will coordinate the development of next-generation DCFC units with PEV manufacturers.

\subsection{Power/Energy Demand and Grid Impact}

When considering the power and energy demand associated with the DCFC complex and the impact of that demand on the grid, there are three important criteria that influence complex design: (1) load factor (i.e., average electrical load divided by peak load in a specified time period), (2) throughput for the charging complex (i.e., number of vehicles charged per time period and peak demand from vehicles charging simultaneously), and (3) available power from the grid, stored energy, and local generation. The interdependencies of these three factors also must be considered when designing DCFC complexes.

For the purpose of this study, two cases were established that define power and energy capacity requirements of urban community and rural corridor charging complexes. These cases provide lower and upper bounds for analysis and are referred to as "minimum capability" and "ultimate capability."

\subsubsection{Power and Energy Demand}

In general, DCFC complexes meeting minimum capability requirements would be expected to have the following characteristics related to power demand:

- Two to six DCFC units, each with a minimum of 50-kW rated capacity

- 100 to $200 \mathrm{~kW}$ of grid power supply, depending on the method of demand management (onsite ES or charge power distribution management).

DCFC complexes meeting ultimate capability requirements would be expected to have the following characteristics:

- Four to 12 DCFC units with up to $350-\mathrm{kW}$ rated capacity

- A minimum of $200 \mathrm{~kW}$ of grid power supply, with additional power supplied as appropriate depending on expected customer demand, power capacity requirements, and cost constraints.

A DCFC complex's cost is largely a function of how it is designed to meet charging power and energy demand. To understand the relationship between DCFC complex design and cost, a design case study was performed to estimate the capital and operating costs of DCFC complexes. Design requirements were specified for hypothetical DCFC complexes located along corridors in rural areas and in urban communities with and without ES and PV systems. Design requirements related to power demand were assumed as follows:

- Minimum capability requirements

- Six DCFC units with 50-kW rated capacity

- 110 and $210 \mathrm{~kW}$ of grid power supply for complexes with and without ES and PV systems, respectively

- Ultimate capability requirements

- Six DCFC units with 350-kW rated capacity

- 160 and 1,060 kW of grid power supply for complexes with and without ES and PV systems, respectively 
For the purpose of this case study, a single DCFC unit is capable of charging one vehicle at a time. Each unit may have multiple cord sets to accommodate different style connectors, but the DCFC units described in this report should be thought of as single-port units. Furthermore, a DCFC unit contains equipment necessary to supply rated power or reduced power to a single connected vehicle, based on power limits communicated to the charging unit by the vehicle and the complex.

The DCFC complex should be designed to meet a defined level of service, which ideally is based on expected consumer demand at a specific location. The level of service dictates power demand and energy throughput of the complex. The following simple assumptions were used to define the level of service requirements for the hypothetical urban community and rural corridor DCFC complexes in the case study:

- Urban locations

- Simultaneous full-power delivery of $20 \mathrm{kWh}$ from each of three units

- Immediately followed by full-power delivery of $20 \mathrm{kWh}$ each from another three units

- Assumes most charge events are opportunity charges (i.e., "top off").

- Rural locations

- Simultaneous full-power delivery of $80 \mathrm{kWh}$ from each of three units

- Immediately followed by full-power delivery of $80 \mathrm{kWh}$ each from another three units

- Assumes most charge events provide a nearly full charge, not opportunity charges.

These requirements are important because they are used to determine the energy storage capacity for complexes with an ES system.

\subsubsection{Grid Impact}

Part of the important design criteria for the DCFC charging complex will be the means by which the complex manages its impact on the electric grid. Because most away-from-home charging will take place during "on peak" time periods, the management of grid load will impact both energy distribution and cost of power demanded during this time. The use of an ES system is a preferred method of managing grid impact because it enables demand reduction and load balancing. The ES system is charged by the grid independent of vehicle charging, so the ES system charge rate can be chosen so that the system has a flat load profile with respect to time, which minimizes negative grid impact. In practicality, this means the ES system typically will be charged at a relatively low, constant rate. This is beneficial for the grid and reduces electricity cost by keeping demand charges down.

There are drawbacks to the use of ES systems. First, capital equipment and maintenance is expensive. Second, by design, the ES system will be discharged to provide power for vehicle charging at a faster rate than it is charged by the grid. If the energy storage capacity of the system is not large enough, relative to customer demand for charging, the system may not be able to keep up. If vehicles arrive for charging when the ES system is fully depleted, the complex will either need to draw higher power from the grid (thus negatively impacting the grid, increasing demand charges, and defeating the purpose of the energy storage system), or truncate the power provided to the vehicles (thus increasing charging time).

Ideally, a charging complex meeting the minimum capability requirements would be designed to achieve a load factor of $30 \%$. A complex meeting ultimate capability requirements ideally would have a load factor of $50 \%$. A lower load factor would mean the complex draws short, intermittent bursts of high power, which may be problematic for the electric grid. The following criteria for load factor were used in the design case study: 
- DCFC complexes with ES and PV systems meeting the minimum and ultimate capability requirements

- Load factor should be $30 \%$ or higher

- DCFC complexes without ES and PV systems meeting the minimum and ultimate capability requirements

- Load factor will be a result of customer demand for charging

- Customer charging demand assumed for DCFC complexes with ES and PV systems will be applied to DCFC complexes without ES and PV systems

\subsection{Renewable Generation}

One way to manage overall costs for charge energy is deployment of renewable forms of electrical generation. Depending on the location, the opportunity for integrating renewable generation could be a significant part of the community and corridor DCFC complex design. For example, in sunny, rural locations, $40 \%$ of actual charge energy conceivably could be supplied from a PV system. Additionally, if vehicles charge infrequently, excess energy generated by the PV system could be supplied to grid services or local facilities. The renewable source need not be co-located, but is more likely to be co-located in rural settings than urban settings.

In the case study, some design configurations have a PV system that contributes energy to charge the ES system. This serves to reduce energy consumption from the grid, which lowers operating costs.

\subsection{Compliance}

DCFC complex designs must comply with local building regulations, including the following:

- The complex must be fully permitted by local building authorities, meeting National Electric Code standards

- The complex must address $\mathrm{ADA}$ accessibility, including the following:

- Vehicle parking

- DCFC unit access

- Access to any other facilities

- The complex must include provisions to ensure point-of-sale security, such as the following:

- Compliance with payment card industry data security standard

- Smartphone apps and other third-party means of identification that may be separate from financial transaction at the DCFC complex.

Experience has shown that each PEV charging infrastructure installation is different. However, by considering the design criteria listed above, it will enable the charging site planner to better balance the existing and future needs of the local PEV drivers, electric utility, authorities having jurisdiction, and investors during installation and operation of a DCFC complex.

\section{SYSTEM SPECIFICATION AND ROUGH-ORDER-OF-MAGNITUDE COST ESTIMATE}

\subsection{Introduction}

The criteria set forth in Section 3 were used in a case study that designed urban community and rural corridor DCFC complex designs to estimate rough-order-of-magnitude costs. To show how costs vary, designs were developed for community and corridor applications with and without ES and PV systems. 
The following subsections provide the system specifications for DCFC complexes in this case study and an associated rough-order-of-magnitude cost estimate for each.

\subsection{With Energy Storage and Photovoltaic Energy Systems}

Urban community and rural corridor DCFC complexes with ES and PV systems were specified, with emphasis on being friendly to the electric grid. To minimize impact on the grid, power demand is minimized through use of an ES system to supply charge power during peak use. Additionally, a PV system is included to provide renewable, low-carbon charging energy. Two DCFC complex configurations (i.e., minimum and ultimate) are presented in anticipation of evolution from current charge rates to much higher charge rates to support long-range vehicles.

Ideally, the first step in the DCFC complex design process would be to identify customer demand for charging. In the absence of consumer demand data, the number of daily charge sessions was chosen to meet the minimum load factor criterion of $30 \%$. The resulting customer utilization of each DCFC complex configuration is shown in Table 2. Researching consumer demand for DC fast charging is a subject of future work.

Table 2. Assumed customer utilization for DCFC complexes with ES and PV systems.

\begin{tabular}{|l|c|c|c|c|}
\hline \multicolumn{1}{|c|}{ Demand Metric } & \multicolumn{2}{c|}{ Minimum } & \multicolumn{2}{c|}{ Ultimate } \\
\hline & Corridor & Community & Corridor & Community \\
\hline Average vehicle charge energy per session $(\mathrm{kWh})$ & 80 & 20 & 80 & 20 \\
\hline Average daily number of charge sessions per port & 2.0 & 6.9 & 4.8 & 16.5 \\
\hline Average daily number of charge sessions per complex & 11.8 & 41.2 & 28.8 & 99.2 \\
\hline Minimum load factor & $30 \%$ & $30 \%$ & $30 \%$ & $30 \%$ \\
\hline
\end{tabular}

As described in Section 3.5.1, for the minimum configuration, both the corridor and community complexes are equipped with six 50-kW charge units. For the ultimate configuration, both the corridor and community complexes are equipped with six $350-\mathrm{kW}$ charge units to charge the larger batteries of long-range battery electric vehicles. System performance requirements for these complexes are presented in Table 3.

Level-of-service requirements, as described in Section 3.5.1, were chosen based on intuition. In practice, these requirements should be derived from analysis of expected consumer demand. In this case study, it was assumed that customer demand for charging would be spaced relatively evenly throughout the day. Therefore, the ES system's energy capacity is sized to provide only two consecutive back-toback charges by three charge units. This means that if three vehicles charged simultaneously and were immediately followed by three more vehicles charging simultaneously, the ES would be fully depleted. Recharge time for the ES system would vary between one and four hours, depending on complex design and PV system output. 
Table 3. Community and corridor charging system performance criteria for DCFC complexes with ES and PV systems.

\begin{tabular}{|c|c|c|c|c|}
\hline \multirow{2}{*}{ Performance Criteria } & \multicolumn{2}{|c|}{ Minimum } & \multicolumn{2}{|c|}{ Ultimate } \\
\hline & Corridor & Community & Corridor & Community \\
\hline \multicolumn{5}{|l|}{ Level of Service Requirements } \\
\hline Maximum number of vehicles charging simultaneously & 3 & 3 & 3 & 3 \\
\hline Maximum number of consecutive sets of vehicles & 2 & 2 & 2 & 2 \\
\hline \multicolumn{5}{|l|}{ Power Requirements } \\
\hline Peak DCFC unit power output to PEV (kW/port) & 50 & 50 & 350 & 350 \\
\hline Peak coincident DCFC unit power to PEVs (kW/complex) & 150 & 150 & 1,050 & 1,050 \\
\hline Complex "house" load demand from grid $(\mathrm{kW})^{(1)}$ & 10 & 10 & 10 & 10 \\
\hline Peak ES system power output (kW) & 50 & 50 & 850 & 850 \\
\hline Peak power drawn from the grid $(\mathrm{kW})$ & 110 & 110 & 210 & 210 \\
\hline \multicolumn{5}{|l|}{ Energy Consumption Based On Monthly Consumer Demand } \\
\hline Energy consumed by PEVs $(\mathrm{kWh} / \mathrm{mo})$ & 28,713 & 25,063 & 70,080 & 60,347 \\
\hline Complex "house" load factor & $70 \%$ & $70 \%$ & $70 \%$ & $70 \%$ \\
\hline Energy consumed by "house" load (kWh/mo) & 5,110 & 5,110 & 5,110 & 5,110 \\
\hline Total energy consumed by complex $(\mathrm{kWh} / \mathrm{mo})$ & 33,823 & 30,173 & 75,190 & 65,457 \\
\hline Grid energy consumed $(\mathrm{kWh} / \mathrm{mo})$ & 24,090 & 24,090 & 45,990 & 45,990 \\
\hline PV energy generated $(\mathrm{kWh} / \mathrm{mo})$ & $9,733^{(2)}$ & $6,083^{(3)}$ & $29,200^{(4)}$ & $19,467^{(5)}$ \\
\hline Percent of energy generated by PV & $29 \%$ & $20 \%$ & $39 \%$ & $30 \%$ \\
\hline \multicolumn{5}{|l|}{ Energy Storage Requirements } \\
\hline ES capacity $(\mathrm{kWh})^{(6)}$ & 208 & 52 & 505 & 126 \\
\hline
\end{tabular}

1 Complex "house" loads are the electrical loads required to operate the DCFC complex. These loads represent power/energy demand from the grid in addition to power/energy transferred to vehicles during charging.

$240 \mathrm{~kW}$ of solar providing 8 equivalent hours of energy at full power per day

$325 \mathrm{~kW}$ of solar providing 8 equivalent hours of energy at full power per day

$4120 \mathrm{~kW}$ of solar providing 8 equivalent hours of energy at full power per day

$580 \mathrm{~kW}$ of solar providing 8 equivalent hours of energy at full power per day

6 ES capacity required to meet level of service requirements plus $30 \%$ additional capacity

An engineering drawing (Figure 10) was created to depict the physical design of a DCFC complex that meets the specifications in Table 3. 


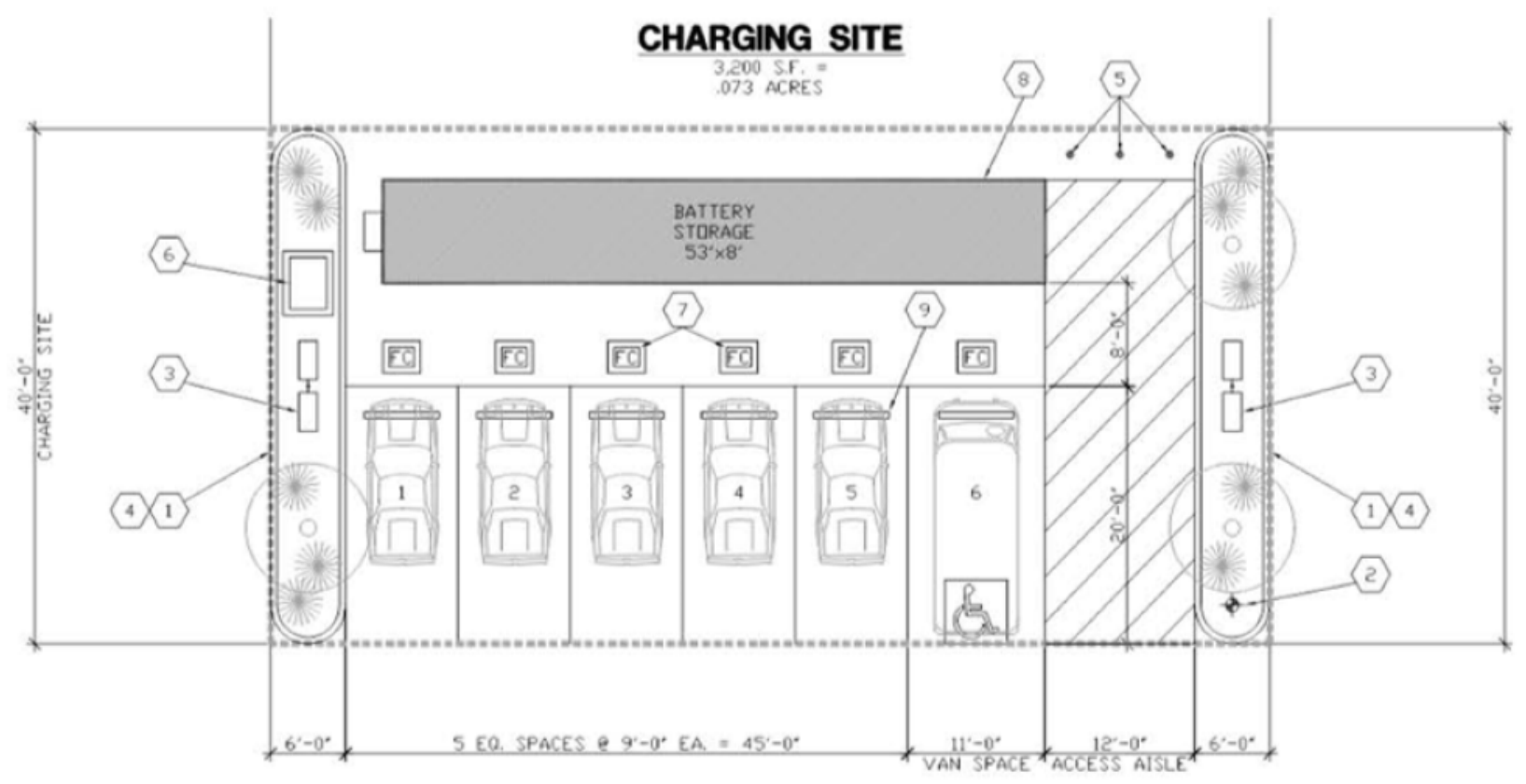

\section{DCFC COMPLEX ISLAND EXHIBIT}

SCALE: $1^{\prime \prime}=10.00$

** ISLAND SCHEME ASSUMES FLUSH CONDITION AT PAVING WITH NO SIDEWALK RAMPING

\section{KEY NOTES}
(1) NEW LANDSCAPED PLANTER AREA
(2) NEW FIRE HYDRANT
(3) NEW PARKING LOT SITE LIGHTING
4. NEW 6" HIGH CONCRETE CURB
5 (5" DIAMETER CONCRETE FILLED PIPE BOLLARD - TYPICAL
6) NEW PAD MOUNTED ELECTRICAL TRANSFORMER
7 NEW FAST CHARGER FOR ELECTRIC VEHICLES - TYPICAL OF 6
7 LOCATIONS
8. NEW BATTERY STORAGE CONTAINER
9 NEW CONCRETE WHEEL STOP - TYPICAL OF 6 LOCATIONS

\section{SITE DESIGN CRITERIA}

CHARGING SITE AREA:

CHARGER PARKING

PROVIDED

TYPICAL PARKING SPACE SIZE:

ACCESSIBLE VAN SPACE SIZE:

ACCESSIBLE VAN AISLE WIDTH:

DRIVE AISLE - FOR TWO WAY TRAFIC ON-SITE:
3,200 S.F. (.073 ACRES)

6 SPACES INCLUDING 1 VAN ACCESSIBLE SPACE

$9^{\prime}-0^{\prime \prime}$ WIDE X $20^{\prime}-0^{\prime \prime}$ LONG

$11^{\prime}-0^{\prime \prime}$ WIDE X $20^{\prime}-0^{\prime \prime}$ LONG $9^{\prime}-0^{\prime \prime}$ MINIMUM WIDTH

24'-0" MINIMUM WIDTH

Figure 10. Engineering drawing for a hypothetical DCFC complex configuration. 
Capital costs were estimated for corridor and community DCFC complexes for both the minimum and ultimate scenarios provided in Table 3. These costs are presented in Table 4, with the assumptions underlying the cost calculations detailed in the notes section.

Table 4. Capital costs of DCFC complexes with ES and PV systems.

\begin{tabular}{|c|c|c|c|c|}
\hline Cost Components With ES and PV & $\begin{array}{l}\text { Minimum } \\
\text { Corridor } \\
\text { Six 50-kW }\end{array}$ & $\begin{array}{l}\text { Minimum } \\
\text { Community } \\
\text { Six 50-kW }\end{array}$ & $\begin{array}{c}\text { Ultimate } \\
\text { Corridor } \\
\text { Six 350-kW }\end{array}$ & $\begin{array}{l}\text { Ultimate } \\
\text { Community } \\
\text { Six 350-kW }\end{array}$ \\
\hline Engineering $^{(1)}$ & $\$ 3,000$ & $\$ 5,000$ & $\$ 4,000$ & $\$ 6,000$ \\
\hline Permit $^{(2)}$ & $\$ 1,000$ & $\$ 3,000$ & $\$ 1,500$ & $\$ 4,500$ \\
\hline Utility interconnection $\operatorname{cost}^{(3)}$ & $\$ 20,000$ & $\$ 20,000$ & $\$ 20,000$ & $\$ 20,000$ \\
\hline Load center and meter section ${ }^{(4)}$ & $\$ 5,500$ & $\$ 5,500$ & $\$ 5,500$ & $\$ 5,500$ \\
\hline $\mathrm{AC} / \mathrm{DC}$ conversion ${ }^{(5)}$ & $\$ 100,000$ & $\$ 100,000$ & $\$ 200,000$ & $\$ 200,000$ \\
\hline ES system & $\$ 83,000^{(6)}$ & $\$ 21,000^{(7)}$ & $\$ 505,000^{(8)}$ & $\$ 126,000^{(9)}$ \\
\hline PV system & $\$ 8,000^{(10)}$ & $\$ 5,000^{(11)}$ & $\$ 24,000^{(12)}$ & $\$ 16,000^{(13)}$ \\
\hline DCFC unit hardware ${ }^{(14)}$ & $\$ 150,000$ & $\$ 150,000$ & $\$ 1,050,000$ & $\$ 1,050,000$ \\
\hline Conduit and cables ${ }^{(15)}$ & $\$ 12,000$ & $\$ 12,000$ & $\$ 15,000$ & $\$ 15,000$ \\
\hline Concrete pads material and labor ${ }^{(16)}$ & $\$ 19,000$ & $\$ 14,000$ & $\$ 20,000$ & $\$ 15,000$ \\
\hline Accessory materials ${ }^{(17)}$ & $\$ 12,500$ & $\$ 12,500$ & $\$ 12,500$ & $\$ 12,500$ \\
\hline Site surface and underground work ${ }^{(18)}$ & $\$ 50,000$ & $\$ 50,000$ & $\$ 50,000$ & $\$ 50,000$ \\
\hline Fixed site improvements ${ }^{(19)}$ & $\$ 40,000$ & $\$ 40,000$ & $\$ 40,000$ & $\$ 40,000$ \\
\hline Equipment installation costs ${ }^{(20)}$ & $\$ 40,000$ & $\$ 40,000$ & $\$ 50,000$ & $\$ 50,000$ \\
\hline Project management & $\$ 30,500^{(21)}$ & $\$ 24,000^{(22)}$ & $\$ 33,500^{(21)}$ & $\$ 26,000^{(22)}$ \\
\hline Total & $\$ 574,500$ & $\$ 502,000$ & $\$ 2,030,500$ & $\$ 1,636,500$ \\
\hline
\end{tabular}

1 Costs include civil, structural and electrical engineering and assume significant reuse of non-site specific work from others

2 Local permit and inspection fees

3 Utility interconnection costs include overhead line extension (2 poles) at distribution voltage and 300kVA distribution transformer

$4600 \mathrm{~A}$ load center with six fused disconnects and separate meter section with current transformers

5 AC/DC converter hardware at $\$ 1.00 / \mathrm{W}$

$6208 \mathrm{kWh}$ at $50 \mathrm{~kW}$ supplied by ES; ES cost of $\$ 400 / \mathrm{kWh}$, ES sized $30 \%$ over required energy

$752 \mathrm{kWh}$ at $50 \mathrm{~kW}$ supplied by ES; ES cost of $\$ 400 / \mathrm{kWh}$, ES sized $30 \%$ over required energy

$8505 \mathrm{kWh}$ at $850 \mathrm{~kW}$ supplied by ES; ES cost of $\$ 1,000 / \mathrm{kWh}$ as a result of high power requirement, ES sized $30 \%$ over required

$9126 \mathrm{kWh}$ at $850 \mathrm{~kW}$ supplied by ES; ES cost of $\$ 1,000 / \mathrm{kWh}$ as a result of very high power requirement, ES sized $30 \%$ over required

$1040 \mathrm{~kW}$ of solar providing 8 equivalent hours of energy at full power, costing $\$ 200 / \mathrm{kW}$

$1125 \mathrm{~kW}$ of solar providing 8 equivalent hours of energy at full power, costing $\$ 200 / \mathrm{kW}$

$12120 \mathrm{~kW}$ of solar providing 8 equivalent hours of energy at full power, costing $\$ 200 / \mathrm{kW}$

$1380 \mathrm{~kW}$ of solar providing 8 equivalent hours of energy at full power, costing $\$ 200 / \mathrm{kW}$

14 DCFC unit hardware only at $\$ 0.50 / \mathrm{W}$ (DC/DC system)

15 Material only for underground and exposed conduit and all power and control cabling based on DCFC complex configuration shown in Figure 10

16 Pads and curbs based on DCFC complex configuration shown in Figure 10 (corridor includes travel costs)

17 Materials include lighting (per Figure 10), landscape plants and irrigation materials, signage and bollards 
18 Costs include grading, trenching/boring, pavement cutting, backfill and surface patching

19 Costs include lighting and signage installation, pavement striping, bollard and irrigation system installation, and landscaping planting

20 Cost include DCFC and ancillary electrical equipment installation

$2115 \%$ of material, labor and subcontract costs (no ES, PV or DCFC equipment cost included)

$2212 \%$ of material, labor and subcontract costs (no ES, PV or DCFC equipment cost included)

Operating costs for corridor and community DCFC charging complexes that meet the requirements of Table 3 are presented in Table 5, with the assumptions underlying the cost calculations being detailed in the notes section.

Table 5. Monthly operating costs of DCFC complexes with ES and PV systems.

\begin{tabular}{|c|c|c|c|c|c|}
\hline \multirow{2}{*}{$\begin{array}{c}\text { Cost Components With ES } \\
\text { and PV }\end{array}$} & \multirow{2}{*}{ Rate } & \multicolumn{2}{|c|}{ Minimum Capability } & \multicolumn{2}{|c|}{ Ultimate Capability } \\
\hline & & Corridor & Community & Corridor & Community \\
\hline Grid demand & $\$ 12 / \mathrm{kW}$ & $\$ 1,320^{(1)}$ & $\$ 1,320^{(1)}$ & $\$ 2,520^{(2)}$ & $\$ 2,520^{(2)}$ \\
\hline Grid energy ${ }^{(3)}$ & $\$ 0.12 / \mathrm{kWh}$ & $\$ 2,891^{(4)}$ & $\$ 2,891^{(5)}$ & $\$ 5,519^{(6)}$ & $\$ 5,519^{(7)}$ \\
\hline Site lease & $\$ 1 / \mathrm{sq}-\mathrm{ft}$ & $\$ 6,000$ & $\$ 6,000$ & $\$ 6,000$ & $\$ 6,000$ \\
\hline Equipment warranty(8) & $1 \% / \mathrm{mo}$ & $\$ 3,410$ & $\$ 2,760$ & $\$ 17,790$ & $\$ 13,920$ \\
\hline Site maintenance $e^{(9)}$ & $\$ 50 /$ unit & $\$ 450$ & $\$ 450$ & $\$ 450$ & $\$ 450$ \\
\hline Communications & $\$ 150$ & $\$ 150$ & $\$ 150$ & $\$ 150$ & $\$ 150$ \\
\hline TOTAL MONTHLY COST & -- & $\$ 14,221$ & $\$ 13,571$ & $\$ 32,428$ & $\$ 28,558$ \\
\hline
\end{tabular}

1 Peak monthly demand $=100 \mathrm{~kW}$ from DCFC plus $10 \mathrm{~kW}$ complex "house" loads. Higher power required to meet service level requirements provided by ES

2 Peak monthly demand $=200 \mathrm{~kW}$ from DCFC plus $10 \mathrm{~kW}$ complex "house" loads. Higher power required to meet service level requirements provided by ES

3 Includes energy from complex "house" loads

4 Load factor of $30 \%$ requires 2.0 charges of $80 \mathrm{kWh}$ per port per day, including use of $40 \%$ of energy supplied by PV

5 Load factor of $30 \%$ requires 6.9 charges of $20 \mathrm{kWh}$ per port per day, including use of $40 \%$ of energy supplied by PV

6 Load factor of $30 \%$ requires 4.8 charges of $80 \mathrm{kWh}$ per port per day, including use of $25 \%$ of energy supplied by PV

7 Load Factor of $30 \%$ requires 16.5 charges of $20 \mathrm{kWh}$ per port per day, including use of $25 \%$ of energy supplied by PV

$81 \%$ of major equipment cost (ES, PV, DCFC, and AC/DC)

9 Total of nine units (six DCFC and one each of ES, PV, and AC/DC)

\subsection{Without Energy Storage and Photovoltaic Energy Systems}

Without using ES or PV systems, a charging complex will be fully dependent on the electric grid for power and energy, which means that the grid power requirement will increase over complexes with ES and PV. To allow for direct comparison, the customer demand assumptions used for the complexes utilizing ES and PV systems are also used here. This customer demand and resulting load factor for each complex configuration is presented in Table 6. 
Table 6. Assumed customer utilization for DCFC complexes without ES and PV systems.

\begin{tabular}{|l|c|c|c|c|}
\hline \multicolumn{1}{|c}{ Demand Metric } & \multicolumn{2}{c|}{ Minimum } & \multicolumn{3}{c|}{ Ultimate } \\
\hline Average vehicle charge energy per session $(\mathrm{kWh})$ & Corridor & Community & Corridor & Community \\
\hline Average daily number of charge sessions per port & 2.0 & 20 & 80 & 20 \\
\hline Average daily number of charge sessions per complex & 11.8 & 41.2 & 28.8 & 99.2 \\
\hline Resulting load factor & $27 \%$ & $24 \%$ & $9 \%$ & $8 \%$ \\
\hline
\end{tabular}

Due to the increased grid power demand for DCFC complexes without ES and PV, the load factor is below the $30 \%$ requirement seen in the previous designs. While a higher load factor would be ideal, it was assumed that customer usage would not vary between charging complexes with and without ES and PV systems.

The system specification for complexes that are fully dependent on the electric grid for power supply is specified in Table 7. Without power provided by an ES system, the maximum grid power was increased from $110 \mathrm{~kW}$ for the corridor complex and $210 \mathrm{~kW}$ for the community complex to $160 \mathrm{~kW}$ and 1,060 $\mathrm{kW}$, respectively. All other aspects of the complex design are the same as for the complexes with ES and PV systems developed in Section 4.2.

Table 7. Community and corridor charging system performance criteria and customer utilization assumptions for DCFC complexes without ES and PV systems.

\begin{tabular}{|c|c|c|c|c|}
\hline \multirow{2}{*}{ Performance Criteria } & \multicolumn{2}{|c|}{ Minimum } & \multicolumn{2}{|c|}{ Ultimate } \\
\hline & Corridor & Community & Corridor & Community \\
\hline \multicolumn{5}{|l|}{ Level of Service Requirements } \\
\hline Maximum number of vehicles charging simultaneously & 3 & 3 & 3 & 3 \\
\hline Maximum number of consecutive sets of vehicles & None & None & None & None \\
\hline \multicolumn{5}{|l|}{ Power Requirements } \\
\hline Peak DCFC unit power output to PEV (kW/port) & 50 & 50 & 350 & 350 \\
\hline Peak coincident DCFC unit power to PEVs (kW/complex) & 150 & 150 & 1,050 & 1,050 \\
\hline Complex "house" load demand from grid (kW) & 10 & 10 & 10 & 10 \\
\hline Peak ES system power output (kW) & 0 & 0 & 0 & 0 \\
\hline Peak power drawn from the grid $(\mathrm{kW})$ & 160 & 160 & 1,060 & 1,060 \\
\hline \multicolumn{5}{|l|}{ Energy Consumption Based On Monthly Consumer Demand } \\
\hline Energy consumed by PEVs (kWh/mo) & 28,713 & 25,063 & 70,080 & 60,347 \\
\hline Complex "house" load factor & $70 \%$ & $70 \%$ & $70 \%$ & $70 \%$ \\
\hline Energy consumed by "house" load (kWh/mo) & 5,100 & 5,100 & 5,100 & 5,100 \\
\hline Total energy consumed by complex $(\mathrm{kWh} / \mathrm{mo})$ & 33,823 & 30,173 & 75,190 & 65,457 \\
\hline Grid energy consumed $(\mathrm{kWh} / \mathrm{mo})$ & 33,823 & 30,173 & 75,190 & 65,457 \\
\hline PV energy generated $(\mathrm{kWh} / \mathrm{mo})$ & 0 & 0 & 0 & 0 \\
\hline Percent of energy generated by PV & $0 \%$ & $0 \%$ & $0 \%$ & $0 \%$ \\
\hline \multicolumn{5}{|l|}{ Energy Storage Requirements } \\
\hline ES capacity (kWh) & 0 & 0 & 0 & 0 \\
\hline
\end{tabular}


Capital costs were estimated for corridor and community DCFC complexes for both the minimum and ultimate scenarios based on criteria and assumptions in Table 7. These costs are presented in Table 8, with the assumptions underlying the cost calculations being detailed in the notes section.

Table 8. Capital costs of DCFC complexes without ES or PV systems.

\begin{tabular}{|c|c|c|c|c|c|}
\hline & Cost Components With Energy Storage & $\begin{array}{c}\text { Minimum } \\
\text { Corridor } \\
\text { Six 50-kW }\end{array}$ & $\begin{array}{l}\text { Minimum } \\
\text { Community } \\
\text { Six 50-kW }\end{array}$ & $\begin{array}{c}\text { Ultimate } \\
\text { Corridor Six } \\
\text { 350-kW }\end{array}$ & $\begin{array}{c}\text { Ultimate } \\
\text { Community } \\
\text { Six 350-kW }\end{array}$ \\
\hline \multicolumn{2}{|c|}{ Engineering ${ }^{(1)}$} & $\$ 3,000$ & $\$ 5,000$ & $\$ 4,000$ & $\$ 6,000$ \\
\hline \multicolumn{2}{|c|}{ Permit $^{(2)}$} & $\$ 1,000$ & $\$ 3,000$ & $\$ 1,500$ & $\$ 4,500$ \\
\hline \multicolumn{2}{|c|}{ Utility interconnection cost } & $\$ 20,000^{(3)}$ & $\$ 20,000^{(3)}$ & $\$ 41,500^{(4)}$ & $\$ 41,500^{(4)}$ \\
\hline \multicolumn{2}{|c|}{ Load center and meter section } & $\$ 5,500^{(5)}$ & $\$ 5,500^{(5)}$ & $\$ 15,000^{(6)}$ & $\$ 15,000^{(6)}$ \\
\hline \multicolumn{2}{|c|}{ AC/DC conversion $(7)$} & $\$ 0$ & $\$ 0$ & $\$ 0$ & $\$ 0$ \\
\hline \multicolumn{2}{|c|}{ ES system $^{(8)}$} & $\$ 0$ & $\$ 0$ & $\$ 0$ & $\$ 0$ \\
\hline \multicolumn{2}{|c|}{ PV system ${ }^{(9)}$} & $\$ 0$ & $\$ 0$ & $\$ 0$ & $\$ 0$ \\
\hline \multicolumn{2}{|c|}{ DCFC unit hardware } & $\$ 180,000^{(10)}$ & $\$ 180,000^{(10)}$ & $\$ 1,470,000^{(11)}$ & $\$ 1,470,000^{(11)}$ \\
\hline \multicolumn{2}{|c|}{ Conduit and cables ${ }^{(12)}$} & $\$ 10,000$ & $\$ 10,000$ & $\$ 14,000$ & $\$ 14,000$ \\
\hline \multicolumn{2}{|r|}{ Concrete pads material and labor ${ }^{(13)}$} & $\$ 15,000$ & $\$ 10,000$ & $\$ 16,000$ & $\$ 11,000$ \\
\hline \multicolumn{2}{|c|}{ Accessory materials ${ }^{(14)}$} & $\$ 12,500$ & $\$ 12,500$ & $\$ 12,500$ & $\$ 12,500$ \\
\hline \multicolumn{2}{|c|}{ Site surface and underground work ${ }^{(15)}$} & $\$ 40,000$ & $\$ 40,000$ & $\$ 40,000$ & $\$ 40,000$ \\
\hline \multicolumn{2}{|c|}{ Fixed site improvements ${ }^{(16)}$} & $\$ 40,000$ & $\$ 40,000$ & $\$ 40,000$ & $\$ 40,000$ \\
\hline \multicolumn{2}{|c|}{ Equipment installation costs ${ }^{(17)}$} & $\$ 35,000$ & $\$ 35,000$ & $\$ 40,000$ & $\$ 40,000$ \\
\hline \multicolumn{2}{|c|}{ Project management } & $\$ 27,500^{(18)}$ & $\$ 21,500^{(19)}$ & $\$ 33,500^{(18)}$ & $\$ 27,000^{(19)}$ \\
\hline \multicolumn{2}{|c|}{ Total } & $\$ 389,500$ & $\$ 382,500$ & $\$ 1,728,000$ & $\$ 1,721,500$ \\
\hline \multicolumn{6}{|c|}{$\begin{array}{l}1 \text { Costs include civil, structural and electrical engineering and assume significant reuse of non-site specific work from other } \\
\text { sites }\end{array}$} \\
\hline \multicolumn{6}{|c|}{2 Local permit and inspection fees } \\
\hline 3 & \multicolumn{5}{|c|}{$\begin{array}{l}\text { Utility interconnection costs include overhead line extension ( } 2 \text { poles) at distribution voltage and } 300 \mathrm{kVA} \text { distribution } \\
\text { transformer }\end{array}$} \\
\hline 4 & \multicolumn{5}{|c|}{$\begin{array}{l}\text { Utility interconnection costs include overhead line extension ( } 2 \text { poles) at distribution voltage and 1,500 kVA distribution } \\
\text { transformer }\end{array}$} \\
\hline 5 & \multicolumn{5}{|c|}{$600 \mathrm{~A}$ load center with six fused disconnects and separate meter section with current transformers } \\
\hline 6 & \multicolumn{5}{|c|}{ 2,000A load center with six fused disconnects and separate meter section with current transformers } \\
\hline \multicolumn{6}{|c|}{ No AC/DC converter installed } \\
\hline 8 & \multicolumn{5}{|l|}{$\begin{array}{l}\text { No AC/DC converter installed } \\
\text { No ES installed }\end{array}$} \\
\hline \multicolumn{6}{|c|}{ No PV installed } \\
\hline 10 & DCFC unit hardware only at $\$ 0.60 / \mathrm{W}(\mathrm{AC} / \mathrm{DC}$ & & & & \\
\hline 11 & DCFC unit hardware only at $\$ 0.70 / \mathrm{W}$ (AC/DC & & & & \\
\hline 12 & $\begin{array}{l}\text { Material only for underground and exposed con } \\
\text { configuration shown in Figure } 10\end{array}$ & nd all power ar & control cabling & sed on DCFC con & \\
\hline 13 & Pads and curbs based on DCFC complex config & $\mathrm{n}$ shown in Fig & e 10 (corridor in & ludes travel costs) & \\
\hline 14 & Materials include lighting (per Figure 10), land & plants and irrig & on materials, sis & age and bollards & \\
\hline 15 & Costs include grading, trenching/boring, pavem & tting, backfill a & 1 surface patchir & & \\
\hline 16 & $\begin{array}{l}\text { Costs include lighting and signage installation, } \\
\text { planting }\end{array}$ & ent striping, b & ard and irrigatio & system installatio & and landscaping \\
\hline 17 & Cost include DCFC and ancillary electrical equi & $t$ installation & & & \\
\hline 18 & $15 \%$ of material, labor and subcontract costs (n & $\mathrm{C}$ equipment $\mathrm{c}$ & t included) & & \\
\hline
\end{tabular}


Operating costs for corridor and community DCFC charging complexes that meet the requirements of Table 7 are presented in Table 9, with the assumptions underlying the cost calculations being detailed in the notes section.

Table 9. Monthly operating costs of DCFC complexes without ES or PV systems.

\begin{tabular}{|l|c|c|c|c|c|}
\hline $\begin{array}{l}\text { Cost Components Without } \\
\text { Energy Storage }\end{array}$ & \multicolumn{2}{|c|}{ Rate } & \multicolumn{2}{c|}{$\begin{array}{c}\text { Minimum Capability } \\
\text { Corridor }\end{array}$} & \multicolumn{2}{c|}{ Ultimate Capability } \\
\hline Grid demand & $\$ 12 / \mathrm{Kw}$ & $\$ 1,920^{(1)}$ & $\$ 1,920^{(1)}$ & $\$ 12,720^{(2)}$ & $\$ 12,720^{(2)}$ \\
\hline Grid energy(3) & $\$ 0.12 / \mathrm{kWh}$ & $\$ 4,059^{(4)}$ & $\$ 3,621^{(5)}$ & $\$ 9,023^{(6)}$ & $\$ 7,855^{(7)}$ \\
\hline Site lease & $\$ 1 / \mathrm{sq}-\mathrm{ft}$ & $\$ 6,000$ & $\$ 6,000$ & $\$ 6,000$ & $\$ 6,000$ \\
\hline Equipment warranty(8) & $1 \%$ & $\$ 1,800$ & $\$ 1,800$ & $\$ 14,700$ & $\$ 14,700$ \\
\hline Site maintenance & $\$ 50 /$ unit & $\$ 300$ & $\$ 300$ & $\$ 300$ & $\$ 300$ \\
\hline Communications & $\$ 150$ & $\$ 150$ & $\$ 150$ & $\$ 150$ & $\$ 150$ \\
\hline TOTAL MONTHLY COST & -- & $\mathbf{\$ 1 4 , 2 2 9}$ & $\mathbf{\$ 1 3 , 7 9 1}$ & $\mathbf{\$ 4 2 , 8 9 3}$ & $\mathbf{\$ 4 1 , 7 2 5}$ \\
\hline
\end{tabular}

1 Peak monthly demand $=150 \mathrm{~kW}$ from DCFC plus $10 \mathrm{~kW}$ complex "house" loads. Higher power required to meet service level requirements provided by ES

2 Peak monthly demand $=1,050 \mathrm{~kW}$ from DCFC plus $10 \mathrm{~kW}$ complex "house" loads. Higher power required to meet service level requirements provided by ES

3 Includes energy from complex "house" loads

4 Customer demand assumed at 2.0 charges of $80 \mathrm{kWh}$ per port per day

5 Customer demand assumed at 6.9 charges of $20 \mathrm{kWh}$ per port per day

6 Customer demand assumed at 14.8 charges of $80 \mathrm{kWh}$ per port per day

7 Customer demand assumed at 16.5 charges of $20 \mathrm{kWh}$ per port per day

$8 \quad 1 \%$ of DCFC equipment cost

\subsection{Discussion of Cost Estimates and Implications for Upgradability}

There are significant differences in the capital and operating costs between the DCFC complex designs presented in earlier sections. A comparison of the minimum capability designs is shown in Table 10 .

Table 10. Summary of approximate costs for DCFC complexes meeting minimum capability requirements.

\begin{tabular}{|l|c|c|c|c|c|}
\hline & \multicolumn{5}{c|}{ Minimum Capability } \\
\hline Design Configuration & $\begin{array}{c}\text { Maximum } \\
\text { Grid Power } \\
(\mathbf{k W}\end{array}$ & $\begin{array}{c}\text { Capital } \\
\text { Cost }\end{array}$ & $\begin{array}{c}\text { Yearly } \\
\text { Operating } \\
\text { Cost }\end{array}$ & $\begin{array}{c}\text { Corridor } \\
\text { Capital }\end{array}$ & $\begin{array}{c}\text { Yearly } \\
\text { Cperating } \\
\text { Cost }\end{array}$ \\
\hline With ES and PV & 110 & $\$ 574,500$ & $\$ 170,600$ & $\$ 502,000$ & $\$ 163,000$ \\
\hline Without ES and PV & 160 & $\$ 392,000$ & $\$ 170,700$ & $\$ 385,500$ & $\$ 165,500$ \\
\hline Difference & & $-\$ 182,500$ & $\$ \mathbf{\$ 1 0 0}$ & $-\$ 116,500$ & $\mathbf{\$ 2 , 5 0 0}$ \\
\hline
\end{tabular}

The ES and PV systems add $\$ 99,500$ to $\$ 165,000$ in capital cost to minimum capability DCFC complexes, but incur very similar operating costs. With ES and PV, a complex will pay less for electrical 
energy and demand, but these savings are offset due to increased maintenance and warranty costs from the added equipment. For this reason, it would be unlikely that a complex owner would benefit from installing ES and PV systems for a station meeting the minimum capability.

Rural corridor and urban community DCFC complexes meeting the ultimate capability requirements in this case study follow a different cost trend. Table 11 shows that both capital and operating costs for systems with and without ES and PV.

Table 11. Summary of approximate costs for DCFC complexes meeting ultimate capability requirements.

\begin{tabular}{|l|c|c|c|c|c|}
\hline & \multicolumn{3}{|c|}{ Ultimate Capability } \\
\hline Design Configuration & $\begin{array}{c}\text { Maximum } \\
\text { Grid Power } \\
\mathbf{( k W )}\end{array}$ & $\begin{array}{c}\text { Capital } \\
\text { Cost }\end{array}$ & $\begin{array}{c}\text { Yearly } \\
\text { Operating } \\
\text { Cost }\end{array}$ & $\begin{array}{c}\text { Capital } \\
\text { Cost }\end{array}$ & $\begin{array}{c}\text { Yearly } \\
\text { Operating } \\
\text { Cost }\end{array}$ \\
\hline With ES and PV & 210 & $\$ 2,030,500$ & $\$ 389,000$ & $\$ 1,636,500$ & $\$ 343,000$ \\
\hline Without ES and PV & 1,060 & $\$ 1,728,000$ & $\$ 514,500$ & $\$ 1,721,500$ & $\$ 500,500$ \\
\hline Difference & & $-\$ 302,500$ & $\mathbf{\$ 1 2 5 , 5 0 0}$ & $\mathbf{\$ 8 5 , 0 0 0}$ & $\mathbf{\$ 1 5 7 , 5 0 0}$ \\
\hline
\end{tabular}

Adding ES and PV systems comes at a high cost in the corridor scenario where over $500 \mathrm{kWh}$ of energy storage is required. The ES system in the community complex is much smaller, which reduces capital costs by around $\$ 400,000$. It is also estimated that with ES and PV, DCFC unit costs will be significantly reduced because the AC/DC conversion is performed in a central unit, allowing the removal of expensive power electronics from each of the units (see Figure 6). Given these reasons and other assumptions used in this case study, the capital cost of a community station with ES and PV is actually lower than without ES and PV.

The operating costs of complexes with ES and PV are much lower, due largely to the difference in power demanded from the grid. Nearly all of the difference between the yearly operating costs of complexes with and without ES and PV is due to the increased power demand charge, which can cost more than $\$ 150,000$ annually for complexes relying solely on the grid for power.

Given the assumptions used in this case study, it is more cost effective to employ the design with ES and PV systems for the ultimate capacity scenario and without ES and PV for the minimum capacity scenario. However, the question of the most cost-effective way to upgrade from the minimum to the ultimate design remains. Examination of Table 4 identified several capital costs that could be pulled ahead to the initial installation. Items like engineering, permitting, utility interconnection, and site surface and underground work could be completed to meet the requirements of the ultimate capability scenario. With this initial investment to prepare the site, the DCFC units and ES and PV systems could be upgraded in the future to create a complex meeting ultimate capability requirements with minimal rework and at lower cost. To that end, the installation costs were calculated for the initial install of the station with $50-\mathrm{kW}$ chargers and the subsequent upgrade to $350-\mathrm{kW}$ chargers. These costs are shown in Table 12. For comparison, costs are shown if the initial installation was completed with and without a future upgrade in mind. 
Table 12. Comparison of installation and upgrade costs for fast charging complexes with and without planning for the upgrade upon initial installation.

\begin{tabular}{|c|c|c|c|c|c|c|}
\hline \multirow[b]{2}{*}{ Upgrade Strategy } & \multicolumn{3}{|c|}{ Corridor } & \multicolumn{3}{|c|}{ Community } \\
\hline & $\begin{array}{c}\text { Initial } \\
\text { Installation } \\
\text { Costs } \\
(50 \mathrm{~kW}, \text { no } \\
\text { ES or PV) }\end{array}$ & $\begin{array}{c}\text { Upgrade } \\
\text { Costs } \\
(350 \mathrm{~kW}, \mathrm{w} / \\
\text { ES and PV) }\end{array}$ & $\begin{array}{c}\text { Overall } \\
\text { Capital } \\
\text { Cost }\end{array}$ & $\begin{array}{c}\text { Initial } \\
\text { Installation } \\
\text { Costs } \\
(50 \mathrm{~kW}, \text { no } \\
\text { ES or PV) }\end{array}$ & $\begin{array}{c}\text { Upgrade } \\
\text { Costs } \\
(350 \mathrm{~kW}, \mathbf{w} / \\
\text { ES and PV) }\end{array}$ & $\begin{array}{c}\text { Overall } \\
\text { Capital } \\
\text { Cost }\end{array}$ \\
\hline Upgrade Not Planned & $\$ 389,300$ & $\$ 1,940,575$ & $\$ 2,329,875$ & $\$ 382,720$ & $\$ 1,549,360$ & $\$ 1,932,080$ \\
\hline $\begin{array}{l}\text { Installed for } \\
\text { Upgradability }\end{array}$ & $\$ 414,025$ & $\$ 1,796,250$ & $\$ 2,210,275$ & $\$ 407,920$ & $\$ 1,408,800$ & $\$ 1,816,720$ \\
\hline Difference & $\$ 24,725$ & $-\$ 144,325$ & $-\$ 119,600$ & $\$ 25,200$ & $-\$ 140,560$ & $-\$ 115,360$ \\
\hline
\end{tabular}

When an upgrade is not planned, the initial installation costs are the same as in Table 8 , and the upgrade costs are slightly cheaper than the comparable costs from Table 4, due to the fact that not every component will need to be replaced. If the complex was built with upgradability in mind, the initial installation would be approximately $\$ 25,000$ higher for both corridor and community complexes, but $\$ 115,000$ to $\$ 120,000$ would be saved in the long run.

In this case study, designs were established based on simple, deterministic assumptions to allow for straight-forward cost estimates. In reality, there is considerable uncertainty about numerous design assumptions and parameters, including the charge power levels that vehicles will draw in the future, the production cost of ES systems, and, perhaps most importantly, the level of customer demand for charging to expect. Prior to making the decision to over-specify components for today's design to accommodate future upgrades, DCFC complex designers should carefully think through the future design to avoid wasted investment. Likewise, care should be taken when deciding whether to use ES and/or PV systems and when sizing those systems to avoid adding expensive equipment that might not have sufficient capacity to meet customer demand for power and energy.

\section{BUSINESS CASE ANALYSIS}

In addition to understanding the relative costs of different DCFC complex designs, it is important to understand the business case for DCFC complexes. A tool was developed by Atlas Public Policy to analyze the business case analysis of urban community and rural corridor charging complexes as part of this case study [37]. This section of the report summarizes the approach and findings of the analysis. Charger usage and costs in the analysis were aligned with those used in Sections 4.2 and 4.3. The analyzed system included onsite ES and PV systems and assumed customer demand for charging has an annual growth rate of $5 \%$ per year.

The business case analysis for this case study considered direct charging revenue only. This means that the only revenue stream to the charging complex owner-operator is a user fee based on energy consumed during vehicle charging. The analysis determined that under most conditions, direct revenue from charging is insufficient for a complex owner/operator to achieve profitability. For each DCFC complex configuration, the amount that customers would need to pay for charging to break even after a 5or 10-year period is shown in Table 13. The table includes the per-kWh cost of electricity, as well as the equivalent fuel cost for a vehicle that averages $30 \mathrm{mpg}$ (assuming a PEV travels 3.5 miles per kilowatthour on average). 
Table 13. End-user costs required for DCFC complex owner-operator to financially break even after 5 or 10 years, assuming revenue comes only from charging fees.

\begin{tabular}{|c|c|c|c|c|c|}
\hline \multirow[b]{2}{*}{$\begin{array}{l}\text { Payback } \\
\text { Period }\end{array}$} & \multirow[b]{2}{*}{ Customer Cost Metric } & \multicolumn{4}{|c|}{ Cost Required to Break Even After Payback Period } \\
\hline & & $\begin{array}{c}\text { Minimum } \\
\text { Corridor } \\
\text { Six 50-kW }\end{array}$ & $\begin{array}{c}\text { Minimum } \\
\text { Community } \\
\text { Six 50-kW }\end{array}$ & $\begin{array}{l}\text { Ultimate } \\
\text { Corridor } \\
\text { Six 350-kW }\end{array}$ & $\begin{array}{c}\text { Ultimate } \\
\text { Community } \\
\text { Six 350-kW }\end{array}$ \\
\hline \multirow{2}{*}{5 Years } & Electricity Cost $(\$ / \mathrm{kWh})$ & $\$ 0.88$ & $\$ 0.93$ & $\$ 1.04$ & $\$ 1.01$ \\
\hline & Equivalent Gasoline Cost (\$/gal) & $\$ 7.54$ & $\$ 7.91$ & $\$ 8.91$ & $\$ 8.65$ \\
\hline \multirow{2}{*}{10 Years } & Electricity Cost $(\$ / \mathrm{kWh})$ & $\$ 0.69$ & $\$ 0.73$ & $\$ 0.77$ & $\$ 0.76$ \\
\hline & Equivalent Gasoline Cost (\$/gal) & $\$ 5.91$ & $\$ 6.25$ & $\$ 6.60$ & $\$ 6.51$ \\
\hline
\end{tabular}

At best, profitability would require customers to pay $\$ 0.69$ per kilowatt-hour to charge their vehicles, which is equivalent to paying $\$ 5.91$ per gallon of gasoline in a vehicle that averages $30 \mathrm{mpg}$. Break-even costs were also calculated for a 15-year payback period, which included an upgrade of the complex from $50-\mathrm{kW}$ chargers to $350-\mathrm{kW}$ chargers after 5 years. The results of this analysis are shown in Table 14 . The installation costs used in this analysis matched those from Table 12. It was assumed that the underground and surface work was initially done for $350-\mathrm{kW}$ capability, as that was found to be the more cost-effective strategy.

Table 14. End-user costs required for DCFC complex to financially break even after 15 years, including an upgrade from minimum to ultimate capability after 5 years.

\begin{tabular}{|c|c|c|}
\hline Customer Cost metric & $\begin{array}{c}\text { Corridor } \\
\text { with } \\
\text { Upgrade }\end{array}$ & $\begin{array}{c}\text { Community } \\
\text { with } \\
\text { Upgrade }\end{array}$ \\
\hline Electricity Cost $(\$ / \mathrm{kWh})$ & $\$ 0.74$ & $\$ 0.75$ \\
\hline Equivalent Gasoline Cost $(\$ / \mathrm{gal})$ & $\$ 6.34$ & $\$ 6.42$ \\
\hline
\end{tabular}

The 15-year break-even costs are similar to those of the 10-year payback period, even with added installation costs that come with upgrading the complex. It is unknown at this time how much of a premium PEV drivers will be willing to pay for fast charging, but it is expected that the costs from these analyses would be too high for the majority of PEV drivers. This finding suggests that significant investments from public and/or private partners may be necessary. These investments could include:

1. Private partner upfront investment: The charging station owner/operator receives an upfront cash transfer from an industry partner per charging station. The perceived value of the charging complex to the industry partner is assumed to be higher than the cash transfer.

2. Public-private partnership: The charging station owner/operator receives an upfront subsidy from the government per charging station. In addition, the owner/operator receives $100 \%$ of the proceeds from carbon credits generated through use of the charging stations, although a national carbon credit market does not currently exist.

The business case analysis is highly sensitive to assumptions for customer utilization. Utilization assumptions made in this case study were purposefully simplified to expedite development of rough cost estimates. Prior to forming firm conclusions or performing further detailed financial analysis, more work is needed to better understand potential customer utilization at individual charging complexes and across entire charging networks. This is especially true for complexes with $350-\mathrm{kW}$ chargers, as these chargers do not yet exist and their usage patterns can only be speculated at present. Once a better understanding of customer demand for charging at DCFC complexes is obtained, DCFC complex design should be 
optimized using advanced optimization tools to thoroughly explore the design space and to understand the lowest-cost designs that meet customer needs. This is the subject of a follow-on project.

\section{REFERENCES}

1. www.tesla.com/supercharger, accessed March 17, 2017.

2. Ibid.

3. Ibid.

4. "Pacific Coast Action Plan on Climate and Energy," October 28, 2013, http://pacificcoastcollaborative.org/Documents/Pacific\%20Coast\%20Climate\%20Action\%20Plan.pdf, accessed December 6, 2016.

5. DOE Alternative Fuels Data Center, http://www.afdc.energy.gov/locator/stations, accessed April 17, 2016.

6. "Regional Planning for Public Charging in San Diego," https://energycenter.org/sites/default/files/docs/nav/programs/pev-planning/san-diego/factsheets/Regional\%20Siting\%20Fact\%20Sheet.pdf, accessed December 6, 2016.

7. "What Location Factors did Highly Utilized DC Fast Chargers have in Common?" INL, May 2015, https://avt.inl.gov/sites/default/files/pdf/EVProj/WhatLocationFactorsDidHighlyUtilizedDCFastChar gersHaveInCommon.pdf, accessed December 6, 2016.

8. "2015 Annual Report, Settlement Year 3 Progress Report to California Public Utilities Commission," NRG EV Services LLC, March 7, 2016, www.cpuc.ca.gov/WorkArea/DownloadAsset.aspx?id=10411, accessed December 8, 2016.

9. "DC Fast Charger Usage in the Pacific Northwest," INL, February 2015, https://avt.inl.gov/sites/default/files/pdf/evse/INL_WCEH_DCFCUsage.pdf, accessed December 6, 2016.

10. "Plugged In: How Americas Charge Their Electric Vehicles," INL, September 2015, https://avt.inl.gov/sites/default/files/pdf/arra/SummaryReport.pdf, accessed December 7, 2016.

11. "Characterize the Demand and Energy Characteristics of Direct Current Fast Chargers," INL, June 2015, https://avt.inl.gov/sites/default/files/pdf/EVProj/CharacterizeDemandAndEnergyDCFC.pdf, accessed October 7, 2016.

12. "What are the Early Experiences in using DC Fast Chargers?" INL, August 2013, https://avt.inl.gov/sites/default/files/pdf/EVProj/126447-30174.dcfc-initexp.pdf, accessed December 7, 2016.

13. "Review of New York State Electric Vehicle Charging Station Market and Policy, Finance, and Market Development Solutions," Coalition for Green Capital, October 2015, https://www.nyserda.ny.gov/-/media/Files/Publications/Research/Transportation/2015-10-EVCharging-Stations-Financing.pdf, accessed April 18, 2017.

14. "What were the Cost Drivers for the Direct Current Fast Charging Installations?" INL, March 2015, https://avt.inl.gov/sites/default/files/pdf/EVProj/WhatWereTheCostDriversForDCFCinstallations.pdf, accessed December 8, 2016.

15. Ibid.

16. Ibid.

17. Tbid. 
18. "Siting and Design Guidelines for Electric Vehicle Supply Equipment," WXY Architecture + Urban Design, November 2012, http://www.transportationandclimate.org/sites/default/files/EV_Siting_and_Design_Guidelines.pdf, accessed April 18, 2017.

19. "The EV Project: Accessibility at Public EV Charging Locations," ECOtality North America, October 2011, https://avt.inl.gov/sites/default/files/pdf/EVProj/EVProjectAccessibilityAtPublicEVChargingLocation s.pdf, accessed December 8, 2016.

20. "Plug-In Electric Vehicle Handbook for Public Charging Station Hosts," Clean Cities, April 2012, http://www.afdc.energy.gov/afdc/pdfs/51227.pdf, accessed December 8, 2016.

21. "Citing Poor Reliability, Netherlands EV Network to Replace 35 DC Quick Chargers," Transport Evolved, April 19, 2017, https://transportevolved.com/2014/01/15/citing-poor-reliability-netherlandsev-network-to-replace-35-dc-quick-chargers/, accessed April 19, 2017.

22. ChargePoint Service Products website, http://www.chargepoint.com/products/service/, accessed April 18, 2017.

23. ABB Electric Vehicle Charging Infrastructure Service website, http://www.abb.com/product/us/9aac176766.aspx, accessed April 18, 2017.

24. Plugged In., pg. 15.

25. Review, pg. 37.

26. Kwan, I., N. Lutsey. P. Slowik, and L. Jin, L., "Identifying the leading regional electric vehicle markets in the United States," ICCT Working Paper 2016-20, November 10, 2016, pg. 2, http://www.theicct.org/sites/default/files/publications/US\%20Regional\%20EV\%20Markets_workingpaper_ICCT_10112016.pdf, accessed December 672016.

27. Kwan, pg. 3.

28. Kwan, pg. 3.

29. Kwan, pg. 11.

30. "What were the Cost Drivers?" pg. 2.

31. Nigro, N., D. Welch, and J. Peace, 2016, "Strategic Planning to Implement Publicly Available EV Charging Stations: A Guide for Businesses and Policymakers," Center for Climate and Energy Solutions, May 2015, http://www.c2es.org/docUploads/ev-charging-guide.pdf, accessed December 7, 2016.

32. Review, pg. 43.

33. http://www.blinknetwork.com/membership-faqs.html, accessed May 23, 2017.

34. https://na.chargepoint.com/charge_point, accessed May 23, 2017.

35. http://www.evsolutions.com/ev-network, accessed May 23, 2017.

36. https://www.evgo.com/charging-plans/, accessed May 23, 2017.

37. Nigro, pgs. 22-26. 


\section{ACKNOWLEDGEMENTS}

The authors gratefully acknowledge that funding support for this project was provided by the U.S. Department of Energy's Vehicle Technologies Office. Additionally, the authors express appreciation to Vehicle Technologies Office staff, members of Electric Power Research Institute's Infrastructure Working Council, and staff at Sacramento Municipal Utility District, Idaho Falls Power, and Eversource Energy for reviewing the assumptions and findings of this study and for providing feedback. 